\title{
A New Hesitant Fuzzy Linguistic TOPSIS Method for Group Multi-Criteria Linguistic Decision Making
}

\author{
Fangling Ren ${ }^{1}$, Mingming Kong ${ }^{2}$ and Zheng Pei ${ }^{2, *}$ \\ 1 College of Mathematics and Computer Science, Yan'an University, Yan'an 716000, Shaanxi, China; \\ renfangling203@163.com \\ 2 Center for Radio Administration \& Technology Development, Xihua University, Chengdu 610039, \\ Sichuan, China; kongming000@126.com \\ * Correspondence: pqyz@263.net
}

Received: 3 November 2017; Accepted: 21 November 2017; Published: 23 November 2017

\begin{abstract}
Hesitant fuzzy linguistic decision making is a focus point in linguistic decision making, in which the main method is based on preference ordering. This paper develops a new hesitant fuzzy linguistic TOPSIS method for group multi-criteria linguistic decision making; the method is inspired by the TOPSIS method and the preference degree between two hesitant fuzzy linguistic term sets (HFLTSs). To this end, we first use the preference degree to define a pseudo-distance between two HFLTSs and analyze its properties. Then we present the positive (optimistic) and negative (pessimistic) information of each criterion provided by each decision maker and aggregate these by using weights of decision makers to obtain the hesitant fuzzy linguistic positive and negative ideal solutions. On the basis of the proposed pseudo-distance, we finally obtain the positive (negative) ideal separation matrix and a new relative closeness degree to rank alternatives. We also design an algorithm based on the provided method to carry out hesitant fuzzy linguistic decision making. An illustrative example shows the elaboration of the proposed method and comparison with the symbolic aggregation-based method, the hesitant fuzzy linguistic TOPSIS method and the hesitant fuzzy linguistic VIKOR method; it seems that the proposed method is a useful and alternative decision-making method.
\end{abstract}

Keywords: group multi-criteria decision making; the TOPSIS method; hesitant fuzzy linguistic term set; pseudo-distance; aggregation operator

\section{Introduction}

In real-world practices, we always face tasks and activities in which it is necessary to use decision-making processes. Generally, decision making is a cognitive process based on different mental and reasoning processes that lead to the choice of a suitable alternative from a set of possible alternatives in a decision situation [1-5]. Because of the inherent complexity and uncertainty of the decision situation or the existence of multiple and conflicting objectives, decision-making problems are complex and difficult; particularly in the era of big data, decision making becomes more complicated because the huge amounts of decision information and alternatives are continuously growing. Many new decision-making methods, such as granular computing techniques [1,6-10], have been proposed for expressing complex or uncertain information in decision-making processes and solving decision-making problems [11-23].

Nowadays, decision-making methods with hesitant fuzzy linguistic term sets (HFLTSs) are a focus point in linguistic decision making (LDM). In many qualitative decision environments, experts think of several possible linguistic values or richer expressions than a single term for an indicator, alternative, variable, and so forth. Accordingly, Rodríguez et al. [24] proposed the concept of HFLTSs to overcome the drawback of existing fuzzy linguistic approaches: the elicitation of single and very simple terms 
to encompass and express the qualitative information. Formally, by taking into account the idea of hesitant fuzzy sets [25] and using extended context-free grammars of a linguistic variable [26], HFLTSs allow us to use different and great flexible forms to represent decision makers' knowledge and preferences in LDM. To make a multi-criteria linguistic decision with HFLTSs, Rodríguez et al. developed the "min_upper" and "max_lower" operators to combine HFLTSs and obtain a linguistic interval for each alternative; then the linguistic intervals are used to build a preference relation between alternatives, and a nondominance choice degree is applied to obtain a solution set of alternatives for the decision problem. The use of the min_upper and max_lower operators produced the first method to deal with hesitant fuzzy linguistic information; since then, many researchers have paid attention to linguistic decision making with HFLTSs, such as in [27], where Lee and Chen proposed likelihood-based comparison relations of HFLTSs and several hesitant fuzzy linguistic aggregation operators to overcome the drawbacks of the methods in [24,28]. In [29], Liu and Rodríguez proposed a fuzzy envelope of HFLTSs for linguistic decision making with HFLTSs. In [30], Montserrat-Adell et al. provided a lattice structure of the set of HFLTSs by means of the operations intersection and connected union, and presented two distances between hesitant fuzzy linguistic sets in the lattice structure, which can be used in linguistic decision making with HFLTSs. In [31], Rodríguez et al. presented a group decision-making model based on HFLTSs. In [28], Wei et al. defined new negation, max-union and min-intersection closed operations for HFLTSs; then they proposed a hesitant fuzzy linguistic weighting averaging operator and a hesitant fuzzy linguistic ordered weighting averaging operator to deal with multi-criteria decision-making problems with HFLTSs. Up to now, operations and extensions of HFLTSs [32-38], hesitant fuzzy linguistic measures and aggregation operators [39-43], and HFLTSs in decision making [44-47] have been widely studied.

In the existing decision-making methods, despite the existence of different decision-making processes in the literature that are composed of different phases, the TOPSIS method proposed in [5] is a useful, important and widely studied multiple-attribute group decision-making method; formally, the TOPSIS method originates from the concept that the selected alternative should have the shortest distance from the positive ideal solution and the farthest distance from the negative ideal solution. Its decision-making process can be expressed in the following five steps [48]: (1) The normalization of the decision matrix; (2) the construction of the weighted normalized decision matrix; (3) the determination of positive and negative ideal solutions; (4) the calculation of separation measures and relative closeness; (5) the ranking of alternatives. Since then, many extended TOPSIS methods have been applied to different multiple-attribute decision making scenarios [49-55]; for example, Chen [56] proposed an extended TOPSIS method for multiple-attribute decision making by considering triangular fuzzy numbers and defining the crisp Euclidean distance between two fuzzy numbers. Similarly, Ashtiani et al. [57] extended the TOPSIS method to solve a multiple-attribute decision-making problem with interval-valued fuzzy sets. He and Gong [58] provided a natural generalization of the TOPSIS method to solve a multiple-attribute decision-making problem with intuitionistic fuzzy sets. Liu et al. [59] developed a new TOPSIS method for decision-making problems with interval-valued intuitionistic fuzzy data. Yue [60] presented a method for solving decision-making problems with an interval number and extended his method to intuitionistic fuzzy sets. In [61], Liang et al. proposed an extended TOPSIS method with linguistic neutrosophic numbers to evaluate investment risks of metallic mines. In [62], Sałabun proposed a new method to estimate the mean error of TOPSIS with the use of a fuzzy reference model.

In [63], Beg and Rashid firstly proposed the TOPSIS method for HFLTSs, in which, the one decision matrix $X$ is calculated by aggregating the opinions of decision makers; the HFLTS positiveand negative-ideal solutions are obtained by the minimization of the minimal and maximal assessments of cost criteria and the maximization of the minimal and maximal assessments of benefit criteria; then the positive-ideal separation matrix (negative-ideal separation matrix) is constructed by distances between $X$ and the positive-ideal (negative-ideal) solution, which can be used to obtain the relative closeness of each alternative and rank all the alternatives. In this paper, we develop a new hesitant 
fuzzy linguistic TOPSIS method for group multi-criteria linguistic decision making, in which, we use the preference degree to define a pseudo-distance between two HFLTSs, and we present the positive and negative information of each criterion provided by each decision maker. Making use of the weighted 2-tuple linguistic aggregation operator, we aggregate the positive and negative information provided by $m$ decision makers to obtain the HFLTS positive- and negative-ideal solutions. Finally, we utilize the pseudo-distance to calculate distances between the assessments of the decision maker and the HFLTS positive- and negative-ideal solutions, and provide a new relative closeness degree of each alternative to rank all the alternatives. The rest of this paper is structured as follows: In Section 2, we briefly review basic concepts and operations of HFLTSs and Beg and Rashid's TOPSIS method. In Section 3, we define the pseudo-distance between two HFLTSs and analyze its properties. We provide the positive and negative information of each criterion and aggregate these to obtain the HFLTS positive- and negative-ideal solutions. Accordingly, we propose the new hesitant fuzzy linguistic TOPSIS method for group multi-criteria linguistic decision making and design an algorithm to carry out hesitant fuzzy linguistic decision making. In Section 4, we utilize an example to illustrate the practicality of the new hesitant fuzzy linguistic TOPSIS method and compare the method with Rodriguez's method [24], Beg and Rashid's method [63] and Liao's method [45]. We conclude the paper in Section 5.

\section{Preliminaries}

In this section, we briefly review concepts and operators of HFLTSs and the TOPSIS method for HFLTSs, and we present the two important hesitant fuzzy linguistic decision-making methods, that is, Rodriguez's method and Beg and Rashid's method.

Definition 1. [24] Let $S$ be a linguistic term set, $S=\left\{s_{0} ; \cdots, s_{g}\right\}$, a HFLTS, $H_{S}$, is an ordered finite subset of the consecutive linguistic terms of $S$.

The basic operations on HFLTSs are as follows [24]:

1. Lower bound: $H_{S^{-}}=\min \left(s_{i}\right)=s_{j}, s_{i} \in H_{S}$ and $s_{i} \geq s_{j} \forall i$;

2. Upper bound: $H_{S^{+}}=\max \left(s_{i}\right)=s_{j}, s_{i} \in H_{S}$ and $s_{i} \leq s_{j} \forall i$;

3. Complement: $H_{S}^{c}=S-H_{S}=\left\{s_{i} \mid s_{i} \in S\right.$ and $\left.s_{i} \notin H_{S}\right\}$;

4. Union: $H_{S}^{1} \cup H_{S}^{2}=\left\{s_{i} \mid s_{i} \in H_{S}^{1}\right.$ or $\left.s_{i} \in H_{S}^{2}\right\}$;

5. Intersection: $H_{S}^{1} \cap H_{S}^{2}=\left\{s_{i} \mid s_{i} \in H_{S}^{1}\right.$ and $\left.s_{i} \in H_{S}^{2}\right\}$;

6. Envelope: $\operatorname{env}\left(H_{S}\right)=\left[H_{S^{-}}, H_{S^{+}}\right]$.

Rodríguez et al. [24] proposed the min_upper and max_lower operators to obtain the core information of hesitant fuzzy linguistic assessments of each alternative; then preference degrees [64] are used to deal with multi-criteria linguistic decision making with HFLTSs. Formally, the min_upper and max_lower operators are as follows: Let $X=\left\{x_{1}, \ldots, x_{n}\right\}$ be a set of alternatives, $C=\left\{c_{1}, \ldots, c_{m}\right\}$ be a set of criteria, $S=\left\{s_{0}, \cdots, s_{g}\right\}$ be a linguistic term set, and $\left\{H_{S}^{j}\left(x_{i}\right) \mid i \in\{1, \ldots, n\}, j \in\{1, \ldots, m\}\right\}$ be a set of HFLTSs. The min_upper operator consists of the following two steps:

1. Apply the upper bound $H_{S^{+}}$for each HFLTS that is associated with each alternative:

$$
H_{S^{+}}\left(x_{i}\right)=\left\{H_{S^{+}}^{1}\left(x_{i}\right), \ldots, H_{S^{+}}^{m}\left(x_{i}\right)\right\}, i \in\{1, \ldots, n\}
$$

2. Obtain the minimum linguistic term for each alternative:

$$
H_{S_{\text {min }}^{+}}\left(x_{i}\right)=\min \left\{H_{S^{+}}^{j}\left(x_{i}\right) \mid j \in\{1, \ldots, m\}\right\}, i \in\{1, \ldots, n\}
$$

The max_lower operator consists of the following two steps: 
1. Apply the lower bound $H_{S^{-}}$for each HFLTS that is associated with each alternative:

$$
H_{S^{-}}\left(x_{i}\right)=\left\{H_{S^{-}}^{1}\left(x_{i}\right), \ldots, H_{S^{-}}^{m}\left(x_{i}\right)\right\}, i \in\{1, \ldots, n\}
$$

2. Obtain the maximum linguistic term for each alternative:

$$
H_{S_{\max }^{-}}\left(x_{i}\right)=\max \left\{H_{S^{-}}^{j}\left(x_{i}\right) \mid j \in\{1, \ldots, m\}\right\}, i \in\{1, \ldots, n\}
$$

Let $H_{\max }^{\prime}\left(x_{i}\right)=\max \left\{H_{S_{\text {min }}^{+}}\left(x_{i}\right), H_{S_{\max }^{-}}\left(x_{i}\right)\right\}$ and $H_{\min }^{\prime}\left(x_{i}\right)=\min \left\{H_{S_{\min }^{+}}\left(x_{i}\right), H_{S_{\max }^{-}}\left(x_{i}\right)\right\}$; then the core information of hesitant fuzzy linguistic assessments of alternative $x_{i}$ is

$$
H^{\prime}\left(x_{i}\right)=\left[H_{\text {min }}^{\prime}\left(x_{i}\right), H_{\text {max }}^{\prime}\left(x_{i}\right)\right]
$$

On the basis of the core information of each alternative and the preference degrees [64] between two sets of core information, the nondominance degree $\mathrm{NDD}_{i}$ of each alternative can be calculated, and the best alternatives are the set of nondominated alternatives $X^{N D}=\left\{x_{i} \mid x_{i} \in X, \mathrm{NDD}_{i}=\right.$ $\left.\max _{x_{j} \in X}\left\{\mathrm{NDD}_{j}\right\}\right\}$.

Example 1. [24] Let $X=\left\{x_{1}, x_{2}, x_{3}\right\}, C=\left\{c_{1}, c_{2}, c_{3}\right\}$ and $S=\left\{\right.$ nothing $\left(s_{0}\right)$, very low $\left(s_{1}\right)$, low $\left(s_{2}\right)$, medium $\left(s_{3}\right)$, high $\left(s_{4}\right)$, very high $\left(s_{5}\right)$, perfect $\left.\left(s_{6}\right)\right\}$. Assessments provided by the decision maker are shown in Table 1.

Table 1. Assessments of $X$ with respect to criteria $C$.

\begin{tabular}{cccc}
\hline & $c_{1}$ & $c_{2}$ & $c_{3}$ \\
\hline$x_{1}$ & $\left\{s_{1}, s_{2}, s_{3}\right\}$ & $\left\{s_{4}, s_{5}\right\}$ & $\left\{s_{4}\right\}$ \\
$x_{2}$ & $\left\{s_{2}, s_{3}\right\}$ & $\left\{s_{3}\right\}$ & $\left\{s_{0}, s_{1}, s_{2}\right\}$ \\
$x_{3}$ & $\left\{s_{4}, s_{5}, s_{6}\right\}$ & $\left\{s_{1}, s_{2}\right\}$ & $\left\{s_{4}, s_{5}, s_{6}\right\}$ \\
\hline
\end{tabular}

The min_upper operator and the max_lower operator are used to obtain the core information of each alternative, such as for alternative $x_{1}, H_{S^{+}}\left(x_{1}\right)=\left\{H_{S^{+}}^{1}\left(x_{1}\right), H_{S^{+}}^{2}\left(x_{1}\right), H_{S^{+}}^{3}\left(x_{1}\right)\right\}=\left\{s_{3}, s_{5}, s_{4}\right\}$, $H_{S^{-}}\left(x_{1}\right)=\left\{H_{S^{-}}^{1}\left(x_{1}\right), H_{S^{-}}^{2}\left(x_{1}\right), H_{S^{-}}^{3}\left(x_{1}\right)\right\}=\left\{s_{1}, s_{4}\right\}, H_{S_{\text {min }}^{+}}\left(x_{1}\right)=\min \left\{s_{3}, s_{5}, s_{4}\right\}=s_{3}, H_{S_{\max }^{-}}\left(x_{1}\right)=$ $\max \left\{s_{1}, s_{4}\right\}=s_{4}, H_{\text {max }}^{\prime}\left(x_{1}\right)=\max \left\{H_{S_{\text {min }}^{+}}\left(x_{1}\right), H_{S_{\max }^{-}}\left(x_{1}\right)\right\}=s_{4}, H_{\min }^{\prime}\left(x_{i}\right)=\min \left\{H_{S_{\min }^{+}}\left(x_{1}\right)\right.$, $\left.H_{S_{\max }^{-}}\left(x_{1}\right)\right\}=s_{3}$ and $H^{\prime}\left(x_{1}\right)=\left[H_{\min }^{\prime}\left(x_{1}\right), H_{\max }^{\prime}\left(x_{1}\right)\right]=\left[s_{3}, s_{4}\right]$. Similarly, $H^{\prime}\left(x_{2}\right)=\left[s_{2}, s_{3}\right]$ and $H^{\prime}\left(x_{3}\right)=\left[s_{2}, s_{4}\right]$.

On the basis of $H^{\prime}\left(x_{1}\right), H^{\prime}\left(x_{2}\right)$ and $H^{\prime}\left(x_{3}\right)$, preference degrees [64] between them can be calculated; for example, for $H^{\prime}\left(x_{1}\right)$ and $H^{\prime}\left(x_{2}\right)$, their preference degree is $p_{12}=P\left(a_{1}>a_{2}\right)=\frac{\max \{4-2,0\}-\max \{3-3,0\}}{(4-3)+(3-2)}=1$ and the binary preference relation between the three alternatives is

$$
P=\left[p_{j j^{\prime}}\right]_{3 \times 3}=\left(\begin{array}{ccc}
- & 1 & 0.667 \\
0 & - & 0.333 \\
0.333 & 0.667 & -
\end{array}\right)
$$

Then the nondominance degree $N D D_{i}$ of $x_{i}$ can be calculated, that is, $N D D_{i}=\min \left\{1-p_{j i}^{S} \mid j \neq i\right\}$ and $p_{j i}^{S}=$ $\max \left\{p_{j i}-p_{i j}, 0\right\}$. Such as $N D D_{1}=\min \left\{1-p_{21}^{S}, 1-p_{31}^{S}\right\}=\min \{1-\max \{0-1,0\}, 1-\max \{0.333-$ $0.667,0\}\}=1$, similarly, $N D D_{2}=0$ and $N D D_{3}=0.666 ; x_{1}$ is selected.

Beg and Rashid proposed an alternative hesitant fuzzy linguistic group decision method, that is, the TOPSIS method for HFLTSs [63]. In the TOPSIS method, the main concepts are a distance between two HFLTSs and the HFLTS positive- and negative-ideal solutions, which can be formalized as follows: Let $H_{S}^{1}$ and $H_{S}^{2}$ be the two HFLTSs on $S=\left\{s_{0}, \cdots, s_{g}\right\}$, env $\left(H_{S}^{1}\right)=\left[s_{p}, s_{q}\right]$ and $e n v\left(H_{S}^{2}\right)=\left[s_{p^{\prime}}, s_{q^{\prime}}\right]$; then the distance between $H_{S}^{1}$ and $H_{S}^{2}$ is 


$$
d\left(H_{S}^{1}, H_{S}^{2}\right)=\left|q^{\prime}-q\right|+\left|p^{\prime}-p\right|
$$

Let $\left\{X^{1}, \cdots, X^{m}\right\}$ be $m$ HFLTS decision matrices provided by $m$ decision makers; then the one decision matrix formed by aggregating the opinions of $m$ decision makers is $X=\left[x_{i j}\right]$, where $x_{i j}=$ $\left[s_{p_{i j}}, s_{q_{i j}}\right]$ and

$$
\begin{aligned}
s_{p_{i j}} & =\min \left\{\min _{l=1}^{m}\left(\max _{S_{i j}}^{l}\right), \max _{l=1}^{m}\left(\min _{S_{i j}}^{l}\right)\right\} \\
s_{q_{i j}} & =\max \left\{\min _{l=1}^{m}\left(\max _{S_{i j}}^{l}\right), \max _{l=1}^{m}\left(\min _{S_{i j}}^{l}\right)\right\}
\end{aligned}
$$

Let $\Omega_{b}$ and $\Omega_{c}$ be collections of benefit and cost criteria, respectively. The HFLTS positive-ideal (negative-ideal) solution $A^{+}\left(A^{-}\right)$is defined as follows:

$$
\begin{aligned}
A^{+}= & {\left[\left(\left(\max _{l=1}^{m}\left(\max _{i} H_{S_{i j}}^{l}\right)\right)\left|j \in \Omega_{b},\left(\min _{l=1}^{m}\left(\min _{i} H_{S_{i j}}^{l}\right)\right)\right| j \in \Omega_{c}\right)\right.} \\
& \left.\left(\left(\max _{l=1}^{m}\left(\max _{i} H_{S_{i j}}^{l}\right)\right)\left|j \in \Omega_{b},\left(\min _{l=1}^{m}\left(\min _{i} H_{S_{i j}}^{l}\right)\right)\right| j \in \Omega_{c}\right)\right] \\
A^{-}= & {\left[\left(\left(\min _{l=1}^{m}\left(\min _{i} H_{S_{i j}}^{l}\right)\right)\left|j \in \Omega_{b},\left(\max _{l=1}^{m}\left(\max _{i} H_{S_{i j}}^{l}\right)\right)\right| j \in \Omega_{c}\right)\right.} \\
& \left.\left(\left(\min _{l=1}^{m}\left(\min _{i} H_{S_{i j}}^{l}\right)\right)\left|j \in \Omega_{b},\left(\max _{l=1}^{m}\left(\max _{i} H_{S_{i j}}^{l}\right)\right)\right| j \in \Omega_{c}\right)\right]
\end{aligned}
$$

where $i=1, \cdots, n$ is the $i$ th considered alternative; $j=1, \cdots, r$ is the $j$ th criterion used for evaluating the alternatives; $A^{+}=\left[V_{1}^{+}, \ldots, V_{r}^{+}\right] ; A^{-}=\left[V_{1}^{-}, \ldots, V_{r}^{-}\right]$; and $V_{j}^{+}$or $V_{j}^{-}$have the form $\left[v_{p_{j}}, v_{q_{j}}\right]$. On the basis of the distance between two HFLTSs and the HFLTS positive- and negative-ideal solutions, the positive-ideal separation matrix $D^{+}$and negative-ideal separation matrix $D^{-}$between $X$ and the positive- and negative-ideal solutions can be calculated as follows:

$$
D^{+}=\left(\begin{array}{c}
d\left(x_{11}, V_{1}^{+}\right)+\cdots+d\left(x_{1 r}, V_{r}^{+}\right) \\
\vdots \\
d\left(x_{n 1}, V_{1}^{+}\right)+\cdots+d\left(x_{n r}, V_{r}^{+}\right)
\end{array}\right), \quad D^{-}=\left(\begin{array}{c}
d\left(x_{11}, V_{1}^{-}\right)+\cdots+d\left(x_{1 r}, V_{r}^{-}\right) \\
\vdots \\
d\left(x_{n 1}, V_{1}^{-}\right)+\cdots+d\left(x_{n r}, V_{r}^{-}\right)
\end{array}\right)
$$

Accordingly, the relative closeness $(R C)$ of each alternative to the ideal solution is as follows:

$$
R C\left(A_{i}\right)=\frac{D_{i}^{-}}{D_{i}^{+}+D_{i}^{-}}
$$

where $D_{i}^{+}=\sum_{j=1}^{r} d\left(x_{i j}, V_{j}^{+}\right)$and $D_{i}^{-}=\sum_{j=1}^{r} d\left(x_{i j}, V_{j}^{-}\right)$. Ranking alternatives are carried out by using the following rule: the greater the value of $R C\left(A_{i}\right)$, the better the alternative $A_{i}$.

\section{The Proposed TOPSIS for HFLTSs}

In this section, we develop a new hesitant fuzzy linguistic TOPSIS method for linguistic decision-making problems. Compared with Beg and Rashid's TOPSIS method, there are three different aspects: (1) We use the preference degree to define a pseudo-distance between two HFLTSs; (2) We present the positive and negative information of each criterion provided by each decision maker; considering weights of decision makers, we aggregate the positive and negative information provided by all decision makers to obtain the HFLTS positive- and negative-ideal solutions, respectively; (3) We propose a new relative closeness degree to rank alternatives. All of these are elaborated on in the following subsections.

\subsection{A Pseudo-Distance between Two HFLTSs}

The preference degree between two HFLTSs has been studied by many researchers $[24,27,28,65]$; generally, we let $H_{S}^{1}$ and $H_{S}^{2}$ be the two HFLTSs on $S=\left\{s_{0}, \cdots, s_{g}\right\}$, env $\left(H_{S}^{1}\right)=\left[s_{p}, s_{q}\right]$ and env $\left(H_{S}^{2}\right)=\left[s_{p^{\prime}}, s_{q^{\prime}}\right]$. Then the preference degree $p\left(H_{S}^{1} \geq H_{S}^{2}\right)$ between $H_{S}^{1}$ and $H_{S}^{2}$ is as follows: 


$$
p\left(H_{S}^{1} \geq H_{S}^{2}\right)=\max \left\{1-\max \left\{\frac{q^{\prime}-p}{(q-p)+\left(q^{\prime}-p^{\prime}\right)}, 0\right\}, 0\right\}
$$

For example, let $S=$ nothing $\left(s_{0}\right)$, very low $\left(s_{1}\right)$, low $\left(s_{2}\right)$, medium $\left(s_{3}\right)$, high $\left(s_{4}\right)$, very high $\left(s_{5}\right)$, perfect $\left.\left(s_{6}\right)\right\}$. For HFLTSs $H_{S}^{1}=\left\{s_{3}, s_{4}, s_{5}\right\}$ and $H_{S}^{2}=\left\{s_{2}, s_{3}, s_{4}\right\}$, env $\left(H_{S}^{1}\right)=\left[s_{3}, s_{5}\right]$ and $\operatorname{env}\left(H_{S}^{2}\right)=\left[s_{2}, s_{4}\right]$; then

$$
p\left(H_{S}^{1} \geq H_{S}^{2}\right)=\max \left\{1-\max \left\{\frac{4-3}{2+2}, 0\right\}, 0\right\}=\frac{3}{4}
$$

Formally, the preference degree between two HFLTSs has the following properties: (1) $0 \leq p\left(H_{S}^{1} \geq H_{S}^{2}\right) \leq 1$; (2) $p\left(H_{S}^{1} \geq H_{S}^{2}\right)+p\left(H_{S}^{2} \geq H_{S}^{1}\right)=1$; (3) if $q^{\prime} \leq p$, then $p\left(H_{S}^{1} \geq H_{S}^{2}\right)=1$; (4) if $q \leq p^{\prime}$, then $p\left(H_{S}^{1} \geq H_{S}^{2}\right)=0$.

Definition 2. Let $H_{S}^{1}$ and $H_{S}^{2}$ be any two HFLTSs on $S=\left\{s_{0}, \cdots, s_{g}\right\}$ and the HFLTS $H_{S}$ on $S$ be the reference set; then we define the following:

$$
d\left(H_{S}^{1}, H_{S}^{2}\right)=\left|p\left(H_{S}^{1} \geq H_{S}\right)-p\left(H_{S}^{2} \geq H_{S}\right)\right|
$$

Intuitively, $d\left(H_{S}^{1}, H_{S}^{2}\right)$ is the difference of preference degrees between two HFLTSs $\left(H_{S}^{1}\right.$ and $H_{S}^{2}$ ) and the the reference set $H_{S}$. According to Equations (7) and (8), we have the following property:

Proposition 1. Let $H_{S}^{1}, H_{S}^{2}$ and $H_{S}^{3}$ be HFLTSs on $S=\left\{s_{0}, \cdots, s_{g}\right\}$ and the HFLTS $H_{S}$ on $S$ be the reference set; then

1. $d\left(H_{S}^{1}, H_{S}^{2}\right) \geq 0$;

2. $\quad d\left(H_{S}^{1}, H_{S}^{2}\right)=d\left(H_{S}^{2}, H_{S}^{1}\right)$;

3. $d\left(H_{S}^{1}, H_{S}^{2}\right) \leq d\left(H_{S}^{1}, H_{S}^{3}\right)+d\left(H_{S}^{3}, H_{S}^{2}\right)$.

Proof. According to Equation (8), $d\left(H_{S}^{1}, H_{S}^{2}\right) \geq 0$ and $d\left(H_{S}^{1}, H_{S}^{2}\right)=d\left(H_{S}^{2}, H_{S}^{1}\right)$ is apparent. Here, we prove Proposition 1. as follows:

$$
\begin{aligned}
d\left(H_{S}^{1}, H_{S}^{2}\right) & =\left|p\left(H_{S}^{1} \geq H_{S}\right)-p\left(H_{S}^{2} \geq H_{S}\right)\right| \\
& =\left|p\left(H_{S}^{1} \geq H_{S}\right)-p\left(H_{S}^{3} \geq H_{S}\right)+p\left(H_{S}^{3} \geq H_{S}\right)-p\left(H_{S}^{2} \geq H_{S}\right)\right| \\
& \leq\left|p\left(H_{S}^{1} \geq H_{S}\right)-p\left(H_{S}^{3} \geq H_{S}\right)\right|+\left|p\left(H_{S}^{3} \geq H_{S}\right)-p\left(H_{S}^{2} \geq H_{S}\right)\right| \\
& =d\left(H_{S}^{1}, H_{S}^{3}\right)+d\left(H_{S}^{3}, H_{S}^{2}\right)
\end{aligned}
$$

That is, $d\left(H_{S}^{1}, H_{S}^{2}\right) \leq d\left(H_{S}^{1}, H_{S}^{3}\right)+d\left(H_{S}^{3}, H_{S}^{2}\right)$ holds.

Proposition 1 means that $d\left(H_{S}^{1}, H_{S}^{2}\right)$ is the pseudo-distance between HFLTSs $H_{S}^{1}$ and $H_{S}^{2}$ on $S=\left\{s_{0}, \cdots, s_{g}\right\}$. In fact, we let $\operatorname{env}\left(H_{S}^{1}\right)=\left[s_{p}, s_{q}\right]$, env $\left(H_{S}^{2}\right)=\left[s_{p^{\prime}}, s_{q^{\prime}}\right]$ and $e n v\left(H_{S}\right)=\left[s_{p_{0}}, s_{q_{0}}\right]$. According to Equation (8), if $H_{S}^{1}=H_{S}^{2}$, then $d\left(H_{S}^{1}, H_{S}^{2}\right)=0$ is apparent. If $d\left(H_{S}^{1}, H_{S}^{2}\right)=0$, we have $p\left(H_{S}^{1} \geq H_{S}\right)=p\left(H_{S}^{2} \geq H_{S}\right)$, and according to Equation (7), we have

$$
\max \left\{1-\max \left\{\frac{q_{0}-p}{(q-p)+\left(q_{0}-p_{0}\right)}, 0\right\}, 0\right\}=\max \left\{1-\max \left\{\frac{q_{0}-p^{\prime}}{\left(q^{\prime}-p^{\prime}\right)+\left(q_{0}-p_{0}\right)}, 0\right\}, 0\right\}
$$

If $p \neq p^{\prime}, q_{0} \leq p$ and $q_{0} \leq p^{\prime}$, then $p\left(H_{S}^{1} \geq H_{S}\right)=p\left(H_{S}^{2} \geq H_{S}\right)=1$; this means that $d\left(H_{S}^{1}, H_{S}^{2}\right)=0$ if and only if $H_{S}^{1}=H_{S}^{2}$ does not always hold. As a special case, in Equation (8), we consider the condition $H_{S}^{2}=H_{S}$, that is, the pseudo-distance between HFLTS $H_{S}^{1}$ and the reference set $H_{S}$. According to property 2 of the preference degree, $p\left(H_{S}^{2} \geq H_{S}\right)+p\left(H_{S} \geq H_{S}^{2}\right)=1$; thus $2 p\left(H_{S} \geq H_{S}\right)=1$, that is, 
$p\left(H_{S} \geq H_{S}\right)=0.5$, and hence the pseudo-distance between $H_{S}^{1}$ and the reference set $H_{S}$ is reduced as follows:

$$
\begin{aligned}
d\left(H_{S}^{1}, H_{S}\right) & =\left|p\left(H_{S}^{1} \geq H_{S}\right)-p\left(H_{S} \geq H_{S}\right)\right|=\left|p\left(H_{S}^{1} \geq H_{S}\right)-0.5\right| \\
& = \begin{cases}0.5, \quad & \text { if } q_{0} \leq p \text { or } q \leq p_{0} \\
\left|\frac{q-p_{0}}{(q-p)+\left(q_{0}-p_{0}\right)}-0.5\right|, & \text { otherwise }\end{cases}
\end{aligned}
$$

Accordingly, we can develop an ordering of HFLTSs on $S=\left\{s_{0}, \cdots, s_{g}\right\}$ on the basis of the reference set; that is, for any two HFLTSs $H_{S}^{1}$ and $H_{S}^{2}$ on $S=\left\{s_{0}, \cdots, s_{g}\right\}$ and the reference set $H_{S}$, $H_{S}^{1} \succeq_{H_{S}} H_{S}^{2}$ if and only if $d\left(H_{S}^{1}, H_{S}\right) \leq d\left(H_{S}^{2}, H_{S}\right)$. Intuitively, the order $\succeq_{H_{S}}$ on HFLTSs means that the closer the HFLTS $H_{S}^{1}$ is to the reference set $H_{S}$, the bigger $H_{S}^{1}$ is. According to Equation (9), it can be easily proved that the order $\succeq_{H_{S}}$ on HFLTSs is a pre-order, that is, $\succeq_{H_{S}}$ satisfies the following:

1. The reflexive property: $H_{S}^{1} \succeq_{H_{S}} H_{S}^{1}$.

2. Transitivity: if $H_{S}^{1} \succeq_{H_{S}} H_{S}^{2}$ and $H_{S}^{2} \succeq_{H_{S}} H_{S}^{3}$, then $H_{S}^{1} \succeq_{H_{S}} H_{S}^{3}$.

We note that if $H F_{S}$ is the set of all HFLTSs on $S=\left\{s_{0}, \cdots, s_{g}\right\}$, then $\left(H F_{S}, \succeq_{H_{S}}\right)$ is a pre-order set.

Example 2. Let $S=\left\{\right.$ nothing $\left(s_{0}\right)$, very low $\left(s_{1}\right)$, low $\left(s_{2}\right)$, medium $\left(s_{3}\right)$, high $\left(s_{4}\right)$, very high $\left(s_{5}\right)$, perfect $\left.\left(s_{6}\right)\right\}$. For the HFLTSs $H_{S}^{1}=\left\{s_{3}, s_{4}, s_{5}\right\}$ and $H_{S}^{2}=\left\{s_{2}, s_{3}, s_{4}\right\}$, and env $\left(H_{S}^{1}\right)=\left[s_{3}, s_{5}\right]$ and env $\left(H_{S}^{2}\right)=$ $\left[s_{2}, s_{4}\right]$, suppose the reference set $H_{S}=\left\{s_{4}, s_{5}\right\}$ and env $\left(H_{S}\right)=\left[s_{4}, s_{5}\right]$. According to Equation (9), we have $d\left(H_{S}^{1}, H_{S}\right)=\left|\frac{5-4}{(5-3)+(5-4)}-0.5\right|=\frac{1}{6}$ and $d\left(H_{S}^{2}, H_{S}\right)=0.5$, that is, $H_{S}^{1} \succeq_{H_{S}} H_{S}^{2}$ as a result of $d\left(H_{S}^{1}, H_{S}\right)=\frac{1}{6}<d\left(H_{S}^{2}, H_{S}\right)=0.5$.

\subsection{The HFLTS Positive- and Negative-Ideal Solutions}

A group multi-criteria hesitant fuzzy linguistic decision-making problem is described as follows: $m$ decision makers $M=\left\{d_{1}, \cdots, d_{m}\right\}$ are asked to assess $n$ alternatives $A=\left\{a_{1}, \cdots, a_{n}\right\}$ with respect to $r$ criteria $C=\left\{c_{1}, \cdots, c_{r}\right\}$ by using HFLTSs on $S=\left\{s_{0}, \cdots, s_{g}\right\}$; formally, decision maker $d_{i}(i=1, \cdots, m)$ provides the decision matrix to express his or her assessments, that is,

$$
D_{i}=\left(e_{j k}^{i}\right)_{n \times r}=\begin{gathered}
c_{1} \\
a_{1} \\
\vdots \\
a_{n}
\end{gathered}\left(\begin{array}{ccc}
e_{11}^{i} & \cdots & c_{1 r}^{i} \\
\vdots & \vdots & \vdots \\
e_{n 1}^{i} & \cdots & e_{n r}^{i}
\end{array}\right)
$$

where $e_{j k}^{i} \in H F_{S}(j \in\{1, \cdots, n\}, k \in\{1, \cdots, r\})$ means that decision maker $d_{i}(i=1, \cdots, m)$ assesses alternative $a_{j}$ with respect to criterion $c_{k}$ by using the HFLTS $e_{j k}^{i}$ on $S=\left\{s_{0}, \cdots, s_{g}\right\}$. On the basis of the decision matrix $D_{i}$, we provide the following definitions.

Definition 3. In the decision matrix $D_{i}$, the positive information of each $c_{k}$ provided by decision maker $d_{i}$ is

$$
C_{i}\left(c_{k}\right)=\left[\max \left\{\min \left(e_{j k}^{i}\right) \mid j=1, \cdots, n\right\}, \max \left\{\max \left(e_{j k}^{i}\right) \mid j=1, \cdots, n\right\}\right]
$$

The negative information of $c_{k}$ provided by decision maker $d_{i}$ is

$$
H_{i}\left(c_{k}\right)=\left[\min \left\{\min \left(e_{j k}^{i}\right) \mid j=1, \cdots, n\right\}, \min \left\{\max \left(e_{j k}^{i}\right) \mid j=1, \cdots, n\right\}\right]
$$

Example 3. Let $A=\left\{a_{1}, a_{2}, a_{3}\right\}$ be a set of three alternatives, $C=\left\{c_{1}, c_{2}, c_{3}\right\}$ be a set of criteria defined for each alternative and $S=\left\{\right.$ nothing $\left(s_{0}\right)$, very low $\left(s_{1}\right)$, low $\left(s_{2}\right)$, medium $\left(s_{3}\right)$, high $\left(s_{4}\right)$, very high $\left(s_{5}\right)$, perfect $\left.\left(s_{6}\right)\right\}$ be the linguistic term set. The assessments provided by decision maker $d_{i}$ are shown in Table 2. 
Table 2. Assessments of $A$ with respect to criteria $C$ provided by decision maker $d_{i}$.

\begin{tabular}{ccccc}
\hline & & $c_{1}$ & $c_{2}$ & $c_{3}$ \\
\hline & $a_{1}$ & $\left\{s_{1}, s_{2}, s_{3}\right\}$ & $\left\{s_{4}, s_{5}\right\}$ & $\left\{s_{3}, s_{4}\right\}$ \\
$d_{i}$ & $a_{2}$ & $\left\{s_{2}, s_{3}\right\}$ & $\left\{s_{3}, s_{4}\right\}$ & $\left\{s_{0}, s_{1}, s_{2}\right\}$ \\
& $a_{3}$ & $\left\{s_{4}, s_{5}, s_{6}\right\}$ & $\left\{s_{1}, s_{2}\right\}$ & $\left\{s_{4}, s_{5}, s_{6}\right\}$ \\
\hline
\end{tabular}

For the criterion $c_{1}$, we have $e_{11}^{i}=\left\{s_{1}, s_{2}, s_{3}\right\}, e_{21}^{i}=\left\{s_{2}, s_{3}\right\}$ and $e_{31}^{i}=\left\{s_{4}, s_{5}, s_{6}\right\}$; hence $\max \left\{\min \left(e_{j 1}^{i}\right) \mid j=1,2,3\right\}=\max \left\{\min \left\{s_{1}, s_{2}, s_{3}\right\}, \min \left\{s_{2}, s_{3}\right\}, \min \left\{s_{4}, s_{5}, s_{6}\right\}\right\}=\max \left\{s_{1}, s_{2}, s_{4}\right\}=s_{4}$, $\max \left\{\max \left(e_{j 1}^{i}\right) \mid j=1,2,3\right\}=\max \left\{\max \left\{s_{1}, s_{2}, s_{3}\right\}, \max \left\{s_{2}, s_{3}\right\}, \max \left\{s_{4}, s_{5}, s_{6}\right\}\right\}=\max \left\{s_{3}, s_{6}\right\}=s_{6}$, $\min \left\{\min \left(e_{j 1}^{i}\right) \mid j=1,2,3\right\}=\min \left\{\min \left\{s_{1}, s_{2}, s_{3}\right\}, \min \left\{s_{2}, s_{3}\right\}, \min \left\{s_{4}, s_{5}, s_{6}\right\}\right\}=\min \left\{s_{1}, s_{2}, s_{4}\right\}=s_{1}$ and $\min \left\{\max \left(e_{j 1}^{i}\right) \mid j=1,2,3\right\}=\min \left\{\max \left\{s_{1}, s_{2}, s_{3}\right\}, \max \left\{s_{2}, s_{3}\right\}, \max \left\{s_{4}, s_{5}, s_{6}\right\}\right\}=\min \left\{s_{3}, s_{6}\right\}=s_{3}$; that is, the positive information and negative information of $c_{1}$ provided by decision maker $d_{i}$ are $C_{i}\left(c_{1}\right)=\left[s_{4}, s_{6}\right]$ and $H_{i}\left(c_{1}\right)=\left[s_{1}, s_{3}\right]$, respectively.

We can notice from Example 3 that the positive information of $c_{k}$ is the optimistic information according to assessments of all alternatives provided by decision maker $d_{i}$; the negative information of $c_{k}$ is the pessimistic information according to assessments of all alternatives provided by decision maker $d_{i}$. Compared with Beg and Rashid's method [63], Equations (1) and (2) are aimed at aggregating the opinions of $m$ decision makers; the result is the one decision matrix $X_{n \times r}$. However, Equations (11) and (12) are used to aggregate the opinions of $n$ alternatives provided by decision maker $d_{i}$ with respect to the criterion $c_{k}$; the results are the optimistic information vector $\left(C_{i}\left(c_{1}\right), \cdots, C_{i}\left(c_{r}\right)\right)$ and the pessimistic information vector $\left(H_{i}\left(c_{1}\right), \cdots, H_{i}\left(c_{r}\right)\right)$ provided by decision maker $d_{i}$ with respect to the criteria.

In a group multi-criteria hesitant fuzzy linguistic decision-making problem, for each criterion $c_{k}$, we denote the positive and negative information of $c_{k}$ as $C_{i}\left(c_{k}\right)=\left[s_{p_{k i}}, s_{q_{k i}}\right]$ and $H_{i}\left(c_{k}\right)=\left[s_{p_{k i}^{\prime}}, s_{q_{k i}^{\prime}}\right]$ provided by decision maker $d_{i}(i=1, \cdots, m)$. We suppose weights $W=\left\{w_{1}, \cdots, w_{m}\right\}$ of $m$ decision makers; then we can use the weighted 2-tuple linguistic aggregation operator [66,67] to obtain the positive and negative information of $c_{k}$ provided by $m$ decision makers, that is,

$$
\begin{aligned}
& C\left(c_{k}\right)=\sum_{i=1}^{m} w_{i} C_{i}\left(c_{k}\right)=\sum_{i=1}^{m} w_{i}\left[s_{p_{k i}}, s_{q_{k i}}\right]=\left[s_{p_{k}}, s_{q_{k}}\right] \\
& H\left(c_{k}\right)=\sum_{i=1}^{m} w_{i} H_{i}\left(c_{k}\right)=\sum_{i=1}^{m} w_{i}\left[s_{p_{k i}^{\prime}}, s_{q_{k i}^{\prime}}\right]=\left[s_{p_{k}^{\prime}}, s_{q_{k}^{\prime}}\right]
\end{aligned}
$$

where $p_{k}=\operatorname{round}\left(\sum_{i=1}^{m} w_{i} p_{k i}\right), q_{k}=\operatorname{round}\left(\sum_{i=1}^{m} w_{i} q_{k i}\right), p_{k}^{\prime}=\operatorname{round}\left(\sum_{i=1}^{m} w_{i} p_{k i}^{\prime}\right)$ and $q_{k}^{\prime}=$ $\operatorname{round}\left(\sum_{i=1}^{m} w_{i} q_{k i}^{\prime}\right)$, and $\operatorname{round}(\cdot)$ is the usual round operation. For example, let the positive information of $c_{1}$ be $C_{1}\left(c_{1}\right)=\left[s_{3}, s_{4}\right], C_{2}\left(c_{1}\right)=\left[s_{4}, s_{6}\right]$ and $C_{3}\left(c_{1}\right)=\left[s_{2}, s_{5}\right]$, which are provided by three decision makers with weights $W=\{0.3,0.5,0.2\}$ in a group multi-criteria hesitant fuzzy linguistic decision-making problem; then the positive information of $c_{1}$ provided by the three decision makers is

$$
\begin{aligned}
C\left(c_{1}\right) & =\sum_{i=1}^{3} w_{i} C_{i}\left(c_{k}\right)=\sum_{i=1}^{m} w_{i}\left[s_{p_{k i}}, s_{q_{k i}}\right]=\left[s_{\operatorname{round}\left(\sum_{i=1}^{3} w_{i} p_{k i}\right)}, s_{\operatorname{round}\left(\sum_{i=1}^{3} w_{i} q_{k i}\right)}\right] \\
& =\left[s_{\operatorname{round}(0.3 \times 3+0.5 \times 4+0.2 \times 2)}, s_{\operatorname{round}(0.3 \times 4+0.5 \times 6+0.2 \times 5)}\right]=\left[s_{\operatorname{round}(3.3)}, s_{\operatorname{round}(5.2)}\right]=\left[s_{3}, s_{5}\right]
\end{aligned}
$$

Definition 4. In a group multi-criteria hesitant fuzzy linguistic decision-making problem, $\left(C\left(c_{1}\right), \cdots, C\left(c_{r}\right)\right)$ and $\left(H\left(c_{1}\right), \cdots, H\left(c_{r}\right)\right)$ are called the HFLTS positive-ideal solution (HPIS) and the HFLTS negative-ideal solution (HNIS), where $C\left(c_{k}\right)$ and $H\left(c_{k}\right)(k=1, \cdots, r)$ are decided by Equations (13) and (14), respectively. 


\subsection{The New Hesitant Fuzzy Linguistic TOPSIS Method}

On the basis of Sections 3.1 and 3.2, we propose a hesitant fuzzy linguistic TOPSIS method that involves the following steps:

Step 1: Let $m$ decision makers $M=\left\{d_{1}, \cdots, d_{m}\right\}$ be asked to assess $n$ alternatives $A=\left\{a_{1}, \cdots, a_{n}\right\}$ with respect to $r$ criteria $C=\left\{c_{1}, \cdots, c_{r}\right\}$ by using HFLTSs on $S=\left\{s_{0}, \cdots, s_{g}\right\}$; decision maker $d_{i}(i=1, \cdots, m)$ with weight $w_{i}$ provides the decision matrix $D_{i}=\left(e_{j k}^{i}\right)_{n \times r}$ to express his or her assessments, where $w_{i} \geq 0$ and $\sum_{i=1}^{m} w_{i}=1$.

Step 2: For each decision matrix $D_{i}=\left(e_{j k}^{i}\right)_{n \times r}$, making use of Equations (11) and (12), we obtain the positive information $C_{i}\left(c_{k}\right)=\left[s_{p_{k i}}, s_{q_{k i}}\right]$ and the negative information $H_{i}\left(c_{k}\right)=\left[s_{p_{k i}^{\prime}} s_{q_{k i}^{\prime}}\right]$ of $c_{k}(k=1, \cdots, r)$. Then we utilize weight $w_{i}(i=1, \cdots, m)$ and Equations (13) and (14) to calculate the positive and negative information $C\left(c_{k}\right)=\left[s_{p_{k}}, s_{q_{k}}\right]$ and $H\left(c_{k}\right)=\left[s_{p_{k}^{\prime}}, s_{q_{k}^{\prime}}\right]$ of each $c_{k}(k=1, \cdots, r)$ provided by $m$ decision makers; we can obtain the HFLTS positive- and negative-ideal solutions as follows:

$$
\text { HPIS }=\left(C\left(c_{1}\right), \cdots, C\left(c_{r}\right)\right), \text { HNIS }=\left(H\left(c_{1}\right), \cdots, H\left(c_{r}\right)\right)
$$

Step 3: We calculate the one decision matrix $D$ by aggregating assessments of decision makers; that is, we use weights $\left(w_{1}, \cdots, w_{m}\right)$ and the weighted 2-tuple linguistic aggregation operator to aggregate $m$ decision matrices $\left(D_{1}, \cdots, D_{m}\right)$ :

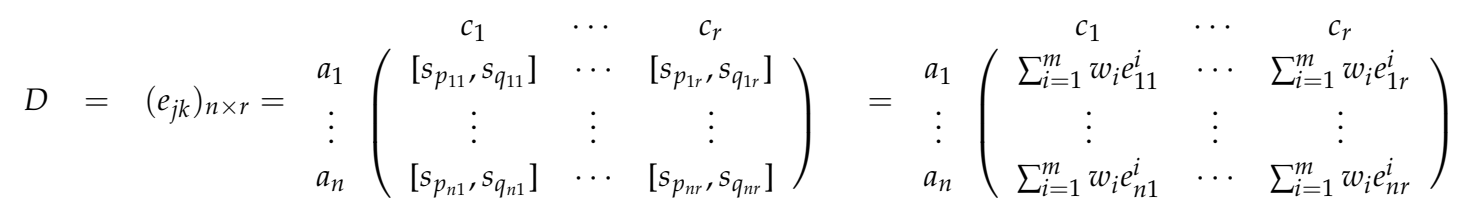

$$
\begin{aligned}
& =\begin{array}{ccc}
a_{1} \\
\vdots \\
a_{n}
\end{array}\left(\begin{array}{ccc}
{\left[\sum_{i=1}^{m} w_{i} s_{p_{11}^{i}}, \sum_{i=1}^{m} w_{i} s_{q_{11}^{i}}\right]} & \cdots & {\left[\sum_{i=1}^{m} w_{i} s_{p_{1 r}^{i}} \sum_{i=1}^{m} w_{i} s_{q_{1 r}^{i}}\right]} \\
\vdots & \vdots & \vdots \\
{\left[\sum_{i=1}^{m} w_{i} s_{p_{n 1}^{i}}^{i} \sum_{i=1}^{m} w_{i} s_{q_{n 1}^{i}}\right]} & \cdots & {\left[\sum_{i=1}^{m} w_{i} s_{p_{n r}^{i}}^{i} \sum_{i=1}^{m} w_{i} s_{q_{n r}^{i}}\right]}
\end{array}\right)
\end{aligned}
$$

where $p_{j k}=\operatorname{round}\left(\sum_{i=1}^{m} w_{i} p_{j k}^{i}\right)$ and $q_{j k}=\operatorname{round}\left(\sum_{i=1}^{m} w_{i} q_{j k}^{i}\right)$ for every $j=1, \cdots, n$ and $k=1, \cdots, r$, respectively, and round $(\cdot)$ is the usual round operation.

Step 4: On the basis of Equation (9) and the HFLTS positive- and negative-ideal solutions of Equation (15), we calculate the positive-ideal separation matrix $D^{+}$and the negative-ideal separation matrix $D^{-}$between assessments of decision makers and the HFLTS positive- and negative-ideal solutions, that is,

$$
\begin{aligned}
& D^{+}=\begin{array}{c}
a_{1} \\
\vdots \\
a_{n}
\end{array}\left(\begin{array}{c}
d\left(e_{11}, C\left(c_{1}\right)\right)+\cdots+d\left(e_{1 r}, C\left(c_{r}\right)\right) \\
\vdots\left(e_{n 1}, C\left(c_{1}\right)\right)+\cdots+d\left(e_{n r}, C\left(c_{r}\right)\right)
\end{array}\right) \\
& D^{-}=\begin{array}{c}
a_{1} \\
\vdots \\
a_{n}
\end{array}\left(\begin{array}{c}
d\left(e_{11}, H\left(c_{1}\right)\right)+\cdots+d\left(e_{1 r}, H\left(c_{r}\right)\right) \\
d\left(e_{n 1}, H\left(c_{1}\right)\right)+\cdots+d\left(e_{n r}, H\left(c_{r}\right)\right)
\end{array}\right)
\end{aligned}
$$

where $d\left(e_{j k}, C\left(c_{k}\right)\right)$ is the pseudo-distance between $e_{j k}=\left[s_{p_{j k}}, s_{q_{j k}}\right]$ and the reference set $C\left(c_{k}\right)$, and $d\left(e_{j k}, H\left(c_{k}\right)\right)$ is the pseudo-distance between $e_{j k}$ and the reference set $H\left(c_{k}\right)$.

If we consider weights $V=\left\{v_{1}, \cdots, v_{r}\right\}$ of $r$ criteria such that $v_{k} \geq 0$ and $\sum_{k=1}^{r} v_{k}=1$, then the positive-ideal separation matrix $D^{+}$and the negative-ideal separation matrix $D^{-}$have the following forms: 


$$
\begin{aligned}
& D^{+}=\begin{array}{c}
a_{1} \\
\vdots \\
a_{n}
\end{array}\left(\begin{array}{c}
v_{1} d\left(e_{11}, C\left(c_{1}\right)\right)+\cdots+v_{r} d\left(e_{1 r}, C\left(c_{r}\right)\right) \\
\vdots \\
v_{1} d\left(e_{n 1}, C\left(c_{1}\right)\right)+\cdots+v_{r} d\left(e_{n r}, C\left(c_{r}\right)\right)
\end{array}\right) \\
& D^{-}=\begin{array}{c}
a_{1} \\
\vdots \\
a_{n}
\end{array}\left(\begin{array}{c}
v_{1} d\left(e_{11}, H\left(c_{1}\right)\right)+\cdots+v_{r} d\left(e_{1 r}, H\left(c_{r}\right)\right) \\
v_{1} d\left(e_{n 1}, H\left(c_{1}\right)\right)+\cdots+v_{r} d\left(e_{n r}, H\left(c_{r}\right)\right)
\end{array}\right)
\end{aligned}
$$

Step 5: The ranking of alternatives in the original TOPSIS method is based on "the shortest distance from the positive-ideal solution and the farthest from the negative-ideal solution"; formally, this is also fulfilled by the relative closeness degree of each alternative in the existing TOPSIS methods. In the paper, on the basis of $D^{+}$and $D^{-}$, we provide the following relative closeness degree $R C\left(a_{j}\right)$ of each alternative:

$$
\begin{aligned}
D_{j}^{+} & =d\left(e_{j 1}, C\left(c_{1}\right)\right)+\cdots+d\left(e_{j r}, C\left(c_{r}\right)\right)=\sum_{k=1}^{r} d\left(e_{j k}, C\left(c_{k}\right)\right) \\
D_{j}^{-} & =d\left(e_{j 1}, H\left(c_{1}\right)\right)+\cdots+d\left(e_{j r}, H\left(c_{r}\right)\right)=\sum_{k=1}^{r} d\left(e_{j k}, H\left(c_{k}\right)\right) \\
D_{\min }^{+} & =\min \left\{D_{1}^{+}, \cdots, D_{n}^{+}\right\}, D_{\max }^{-}=\max \left\{D_{1}^{-}, \cdots, D_{n}^{-}\right\} \\
R C\left(a_{j}\right) & =\frac{D_{\min }^{+}}{D_{j}^{+}}+\frac{D_{j}^{-}}{D_{\max }^{-}}
\end{aligned}
$$

Formally, the relative closeness degree $R C\left(a_{j}\right)$ of each alternative $a_{j}$ is in $[0,2]$. More importantly, $R C\left(a_{j}\right)$ is a monotone function in its components; that is, $R C\left(a_{j}\right)$ is increasing for $D_{j}^{-}$and decreasing for $D_{j}^{+}$. This is coincidental with "the shortest distance from the positive-ideal solution and the farthest from the negative-ideal solution".

Step 6: Rank all the alternatives $a_{j}(j=1, \cdots, n)$ according to the relative closeness degree $R C\left(a_{j}\right)$. The greater the value $R C\left(a_{j}\right)$, the better the alternative $a_{j}$; that is, for any $j, j^{\prime} \in\{1, \cdots, n\}, a_{j} \succeq a_{j^{\prime}}$ if and only if $R C\left(a_{j}\right) \geq R C\left(a_{j^{\prime}}\right)$.

On the basis of the above-mentioned six steps, we provide the following algorithm to implement the new hesitant fuzzy linguistic TOPSIS method to solve hesitant fuzzy linguistic group multi-criteria decision-making problems.

\section{Numerical Example}

In this section, we utilize an example to illustrate the practicality of the new hesitant fuzzy linguistic TOPSIS method, and compare it with Rodriguez's method [24], Beg and Rashid's method [63] and Liao's method [45].

Example 4. Let $A=\left\{a_{1}, a_{2}, a_{3}\right\}$ be a set of three alternatives and $C=\left\{c_{1}, c_{2}, c_{3}\right\}$ be a set of criteria defined for each alternative. Three decision makers $M=\left\{d_{1}, d_{2}, d_{3}\right\}$ with weights $W=\{0.3,0.5,0.2\}$ use linguistic terms $S=\left\{\right.$ nothing $\left(s_{0}\right)$, very low $\left(s_{1}\right)$, low $\left(s_{2}\right)$, medium $\left(s_{3}\right)$, high $\left(s_{4}\right)$, very high $\left(s_{5}\right)$, perfect $\left.\left(s_{6}\right)\right\}$ to assess three alternatives with respect to three criteria (shown in Table 3 ). 
Table 3. The hesitant fuzzy linguistic assessments of alternatives provided by decision makers.

\begin{tabular}{ccccc}
\hline & & $c_{1}$ & $c_{2}$ & $c_{3}$ \\
\hline \multirow{4}{*}{$d_{1}(0.3)$} & $a_{1}$ & $\left\{s_{4}, s_{5}, s_{6}\right\}$ & $\left\{s_{5}, s_{6}\right\}$ & $\left\{s_{4}, s_{5}, s_{6}\right\}$ \\
& $a_{2}$ & $\left\{s_{4}, s_{5}, s_{6}\right\}$ & $\left\{s_{4}, s_{5}, s_{6}\right\}$ & $\left\{s_{1}, s_{2}, s_{3}\right\}$ \\
& $a_{3}$ & $\left\{s_{5}, s_{6}\right\}$ & $\left\{s_{4}, s_{5}, s_{6}\right\}$ & $\left\{s_{6}\right\}$ \\
\hline \multirow{4}{*}{$d_{2}(0.5)$} & $a_{1}$ & $\left\{s_{4}, s_{5}\right\}$ & $\left\{s_{5}, s_{6}\right\}$ & $\left\{s_{3}, s_{4}, s_{5}\right\}$ \\
& $a_{2}$ & $\left\{s_{3}, s_{4}, s_{5}\right\}$ & $\left\{s_{4}, s_{5}\right\}$ & $\left\{s_{2}, s_{3}\right\}$ \\
& $a_{3}$ & $\left\{s_{2}, s_{3}, s_{4}\right\}$ & $\left\{s_{3}, s_{4}\right\}$ & $\left\{s_{4}, s_{5}\right\}$ \\
\hline \multirow{4}{*}{$d_{3}(0.2)$} & $a_{1}$ & $\left\{s_{3}, s_{4}\right\}$ & $\left\{s_{4}, s_{5}\right\}$ & $\left\{s_{5}, s_{6}\right\}$ \\
& $a_{2}$ & $\left\{s_{5}, s_{6}\right\}$ & $\left\{s_{3}, s_{4}\right\}$ & $\left\{s_{3}, s_{4}\right\}$ \\
& $a_{3}$ & $\left\{s_{4}, s_{5}\right\}$ & $\left\{s_{3}, s_{4}, s_{5}\right\}$ & $\left\{s_{5}, s_{6}\right\}$ \\
\hline
\end{tabular}

By using the new hesitant fuzzy linguistic TOPSIS method (Algorithm 1), the hesitant fuzzy linguistic group multi-criteria decision making can be carried out as follows:

(1) On the basis of Table 3, we can obtain three decision matrices provided by the three decision makers, as follows:

$$
\begin{aligned}
& D_{1}=\left(\begin{array}{lll}
{\left[s_{4}, s_{6}\right]} & {\left[s_{5}, s_{6}\right]} & {\left[s_{4}, s_{6}\right]} \\
{\left[s_{4}, s_{6}\right]} & {\left[s_{4}, s_{6}\right]} & {\left[s_{1}, s_{3}\right]} \\
{\left[s_{5}, s_{6}\right]} & {\left[s_{4}, s_{6}\right]} & {\left[s_{6}, s_{6}\right]}
\end{array}\right), D_{2}=\left(\begin{array}{lll}
{\left[s_{4}, s_{5}\right]} & {\left[s_{5}, s_{6}\right]} & {\left[s_{3}, s_{5}\right]} \\
{\left[s_{3}, s_{5}\right]} & {\left[s_{4}, s_{5}\right]} & {\left[s_{2}, s_{3}\right]} \\
{\left[s_{2}, s_{4}\right]} & {\left[s_{3}, s_{4}\right]} & {\left[s_{4}, s_{5}\right]}
\end{array}\right) \\
& D_{3}=\left(\begin{array}{lll}
{\left[s_{3}, s_{4}\right]} & {\left[s_{4}, s_{5}\right]} & {\left[s_{5}, s_{6}\right]} \\
{\left[s_{5}, s_{6}\right]} & {\left[s_{3}, s_{4}\right]} & {\left[s_{3}, s_{4}\right]} \\
{\left[s_{4}, s_{5}\right]} & {\left[s_{3}, s_{5}\right]} & {\left[s_{5}, s_{6}\right]}
\end{array}\right)
\end{aligned}
$$

(2) On the basis of Equations (11)-(14), we can calculate the positive and negative information of each criterion provided by the three decision makers. For example, for criterion $c_{1}$, the positive and negative information provided by decision maker $d_{1}$ are $C_{1}\left(c_{1}\right)=\left[\max \left\{s_{4}, s_{5}\right\}, \max \left\{s_{6}\right\}\right]=$ $\left[s_{5}, s_{6}\right]$ and $H_{1}\left(c_{1}\right)=\left[\min \left\{s_{4}, s_{5}\right\}, \min \left\{s_{6}\right\}\right]=\left[s_{4}, s_{6}\right] ;$ similarly, $C_{2}\left(c_{1}\right)=\left[s_{4}, s_{5}\right], H_{2}\left(c_{1}\right)=$ $\left[s_{2}, s_{4}\right], C_{3}\left(c_{1}\right)=\left[s_{5}, s_{6}\right]$ and $H_{3}\left(c_{1}\right)=\left[s_{3}, s_{4}\right]$. Making use of the weights $(0.3,0.5,0.2)$, we obtain $C\left(c_{1}\right)=\left[s_{\text {round }}(0.3 \times 5+0.5 \times 4+0.2 \times 5), s_{\text {round }}(0.3 \times 6+0.5 \times 5+0.2 \times 6)\right]=\left[s_{5}, s_{6}\right]$ and $H\left(c_{1}\right)=$ $\left[s_{\text {round }}(0.3 \times 4+0.5 \times 2+0.2 \times 3), s_{\text {round }}(0.3 \times 6+0.5 \times 4+0.2 \times 4)\right]=\left[s_{3}, s_{5}\right]$; the others are shown in Table 4.

Table 4. The positive and negative information of each criterion provided by decision makers.

\begin{tabular}{ccccc}
\hline & & $c_{1}$ & $c_{2}$ & $c_{3}$ \\
\hline$d_{1}(0.3)$ & $C_{1}$ & {$\left[s_{5}, s_{6}\right]$} & {$\left[s_{5}, s_{6}\right]$} & {$\left[s_{6}, s_{6}\right]$} \\
& $H_{1}$ & {$\left[s_{4}, s_{6}\right]$} & {$\left[s_{4}, s_{6}\right]$} & {$\left[s_{1}, s_{3}\right]$} \\
\hline$d_{2}(0.5)$ & $C_{2}$ & {$\left[s_{4}, s_{5}\right]$} & {$\left[s_{5}, s_{6}\right]$} & {$\left[s_{4}, s_{5}\right]$} \\
& $H_{2}$ & {$\left[s_{2}, s_{4}\right]$} & {$\left[s_{3}, s_{4}\right]$} & {$\left[s_{2}, s_{3}\right]$} \\
\hline$d_{3}(0.2)$ & $C_{3}$ & {$\left[s_{5}, s_{6}\right]$} & {$\left[s_{4}, s_{5}\right]$} & {$\left[s_{5}, s_{6}\right]$} \\
& $H_{3}$ & {$\left[s_{3}, s_{4}\right]$} & {$\left[s_{3}, s_{4}\right]$} & {$\left[s_{3}, s_{4}\right]$} \\
\hline & $C$ & {$\left[s_{5}, s_{6}\right]$} & {$\left[s_{5}, s_{6}\right]$} & {$\left[s_{5}, s_{6}\right]$} \\
& $H$ & {$\left[s_{3}, s_{5}\right]$} & {$\left[s_{3}, s_{5}\right]$} & {$\left[s_{2}, s_{3}\right]$} \\
\hline
\end{tabular}

(3) On the basis of the weights $(0.3,0.5,0.2)$, we aggregate $D_{1}, D_{2}$ and $D_{3}$ to obtain the one decision matrix $D$, that is,

$$
D=0.3 D_{1}+0.5 D_{2}+0.2 D_{3}=\left(\begin{array}{ccc}
{\left[s_{4}, s_{5}\right]} & {\left[s_{5}, s_{6}\right]} & {\left[s_{4}, s_{6}\right]} \\
{\left[s_{4}, s_{6}\right]} & {\left[s_{4}, s_{5}\right]} & {\left[s_{2}, s_{3}\right]} \\
{\left[s_{3}, s_{5}\right]} & {\left[s_{3}, s_{5}\right]} & {\left[s_{5}, s_{6}\right]}
\end{array}\right)
$$


(4) On the basis of the one decision matrix $D$ and the HFLTS positive- and negative-ideal solutions HPIS $=\left(\left[s_{5}, s_{6}\right],\left[s_{5}, s_{6}\right],\left[s_{5}, s_{6}\right]\right)$ and HNIS $=\left(\left[s_{3}, s_{5}\right],\left[s_{3}, s_{5}\right],\left[s_{2}, s_{3}\right]\right)$, we use Equations (9), (17) and (18) to calculate the positive- and negative-ideal separation matrices $D^{+}$and $D^{-}$, that is,

$$
\begin{aligned}
D^{+}= & \left(\begin{array}{c}
d\left(\left[s_{4}, s_{5}\right],\left[s_{5}, s_{6}\right]\right)+d\left(\left[s_{5}, s_{6}\right],\left[s_{5}, s_{6}\right]\right)+d\left(\left[s_{4}, s_{6}\right],\left[s_{5}, s_{6}\right]\right) \\
d\left(\left[s_{4}, s_{6}\right],\left[s_{5}, s_{6}\right]\right)+d\left(\left[s_{4}, s_{5}\right],\left[s_{5}, s_{6}\right]\right)+d\left(\left[s_{2}, s_{3}\right],\left[s_{5}, s_{6}\right]\right) \\
d\left(\left[s_{3}, s_{5}\right],\left[s_{5}, s_{6}\right]\right)+d\left(\left[s_{3}, s_{5}\right],\left[s_{5}, s_{6}\right]\right)+d\left(\left[s_{5}, s_{6}\right],\left[s_{5}, s_{6}\right]\right)
\end{array}\right) \\
\doteq & \left(\begin{array}{c}
0.5+0+0.17 \\
0.17+0.5+0.5 \\
0.5+0.5+0
\end{array}\right)=\left(\begin{array}{c}
0.67 \\
1.17 \\
1
\end{array}\right) \\
D^{-}= & \left(\begin{array}{c}
d\left(\left[s_{4}, s_{5}\right],\left[s_{3}, s_{5}\right]\right)+d\left(\left[s_{5}, s_{6}\right],\left[s_{3}, s_{5}\right]\right)+d\left(\left[s_{4}, s_{6}\right],\left[s_{2}, s_{3}\right]\right) \\
d\left(\left[s_{4}, s_{6}\right],\left[s_{3}, s_{5}\right]\right)+d\left(\left[s_{4}, s_{5}\right],\left[s_{3}, s_{5}\right]\right)+d\left(\left[s_{2}, s_{3}\right],\left[s_{2}, s_{3}\right]\right) \\
d\left(\left[s_{3}, s_{5}\right],\left[s_{3}, s_{5}\right]\right)+d\left(\left[s_{3}, s_{5}\right],\left[s_{3}, s_{5}\right]\right)+d\left(\left[s_{5}, s_{6}\right],\left[s_{2}, s_{3}\right]\right)
\end{array}\right) \\
= & \left(\begin{array}{c}
0.17+0.5+0.5 \\
0.25+0.17+0 \\
0+0+0.5
\end{array}\right)=\left(\begin{array}{c}
1.17 \\
0.42 \\
0.5
\end{array}\right)
\end{aligned}
$$

(5) On the basis of Equations (21)-(24), we obtain the relative closeness degrees $R C\left(a_{j}\right)$ of each alternative, which are shown in Table 5.

Table 5. The relative closeness degrees of alternatives.

\begin{tabular}{cccc}
\hline & $\boldsymbol{D}_{j}^{+}$ & $\boldsymbol{D}_{j}^{-}$ & $\boldsymbol{R C}\left(\boldsymbol{a}_{j}\right)$ \\
\hline$a_{1}$ & 0.67 & 1.17 & $\frac{0.67}{0.67}+\frac{1.17}{1.17}=2$ \\
$a_{2}$ & 1.17 & 0.42 & $\frac{0.67}{1.17}+\frac{0.42}{1.17} \doteq 0.92$ \\
$a_{3}$ & 1 & 0.5 & $\frac{0.67}{1}+\frac{0.5}{1.17} \doteq 1.1$ \\
\hline \multicolumn{3}{c}{$D_{\min }^{+}=0.67$} & $D_{\text {max }}^{-}=1.17$ \\
\hline
\end{tabular}

(6) According to $R C\left(a_{j}\right)$ of each alternative in Table 5 , we obtain that the ranking of alternatives is $a_{1} \succeq a_{3} \succeq$ $a_{2}$, given that $R C\left(a_{1}\right)>R C\left(a_{3}\right)>R C\left(a_{2}\right)$, and that $a_{1}$ is the the most satisfying alternative.

In the following, we compare the new hesitant fuzzy linguistic TOPSIS method with Rodriguez's method [24], Beg and Rashid's method [63] and Liao's method [45] by using Example 4, in which, because Rodriguez's method and Liao's method are used to carry out the hesitant fuzzy linguistic multi-criteria decision making, we use the decision matrix $D_{1}$ provided by decision maker $d_{1}$ as the hesitant fuzzy linguistic multi-criteria of decision making for comparison with the three methods. Then we use Beg and Rashid's method in Example 4 and compare this with the proposed method. 


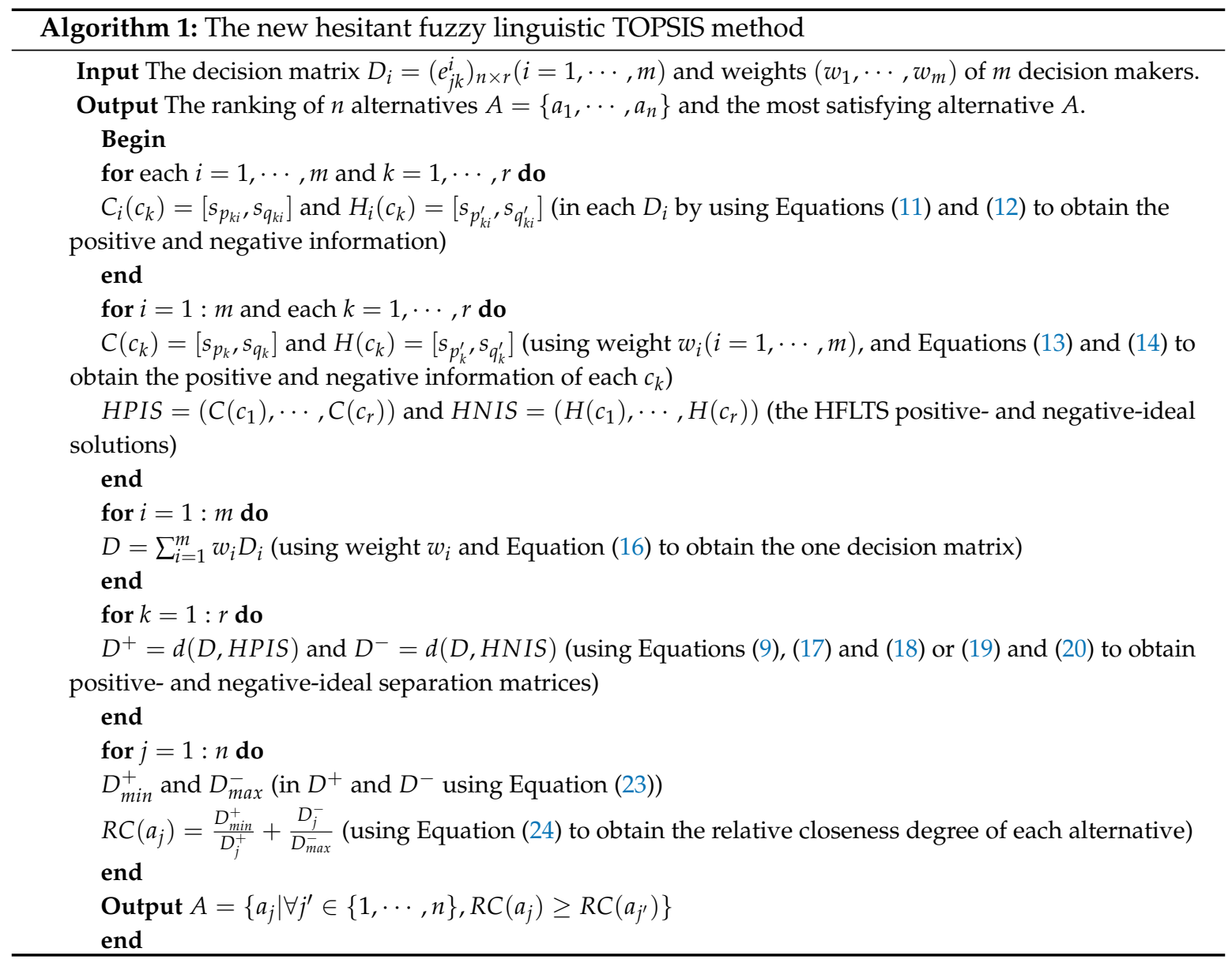

\subsection{Comparison with Rodriguez's and Liao's Methods}

Rodriguez's method is also called the symbolic aggregation-based method [24] and Liao's method is called the hesitant fuzzy linguistic VIKOR (HFL-VIKOR) method [45]; here, we use the decision matrix $D_{1}$ provided by decision maker $d_{1}$ in Example 4 to show the symbolic aggregation-based method, the HFL-VIKOR method and the proposed method, and carry out a comparison of the three methods, as follows:

(1) The positive- and negative-ideal solutions: The symbolic aggregation-based method utilizes min_upper and max_lower operators to construct the core information of each alternative. For example, for $a_{1}$ of the decision matrix $D_{1}$, the min bounds of $c_{1}, c_{2}$ and $c_{3}$ are $s_{4}, s_{5}$ and $s_{4}$; thus the min_upper of $a_{1}$ is $s_{5}$. The max bounds of $c_{1}, c_{2}$ and $c_{3}$ are $s_{6}, s_{6}$ and $s_{6}$; thus the max -lower of $a_{1}$ is $s_{6}$, and hence the core information of $a_{1}$ is $\left[s_{5}, s_{6}\right]$. Intuitively, the core information reduces HFLTSs of each alternative with respect to the criteria into a linguistic interval.

The HFL-VIKOR method utilizes the score function and the variance function of HFLTSs [45] to rank HFLTSs of all alternatives with respect to each criterion; for example, for $c_{3}$ of the decision matrix $D_{1}$, according to the score functions and the variance functions of $\left[s_{4}, s_{6}\right],\left[s_{1}, s_{3}\right]$ and $\left[s_{6}, s_{6}\right]$, we obtain $\left[s_{6}, s_{6}\right]>\left[s_{4}, s_{6}\right]>\left[s_{1}, s_{3}\right]$; hence the positive- and negative-ideal solutions of $c_{3}$ in the decision matrix $D_{1}$ are $\left[s_{6}, s_{6}\right]$ and $\left[s_{1}, s_{3}\right]$, respectively.

The proposed method uses Equations (11) and (12) to obtain the positive and negative information of each criterion. Intuitively, the positive information of each criterion in the decision matrix $D_{1}$ is also the optimistic information of all the alternatives provided by decision maker $d_{1}$, and the negative information of each criterion is the pessimistic information of all the alternatives, which can be understood as the positive- and negative-ideal solutions provided by decision maker $d_{1}$. Table 6 shows the comparison of the three methods. 
Table 6. The positive- and negative-ideal solutions of the three methods.

\begin{tabular}{cccc}
\hline & The Positive-Ideal Solution & The Negative-Ideal Solution & The Core Information \\
\hline The method [24] & - & - & $\left(\left[s_{5}, s_{6}\right],\left[s_{3}, s_{4}\right],\left[s_{6}, s_{6}\right]\right)$ \\
The method $[45]$ & $\left(\left[s_{5}, s_{6}\right],\left[s_{5}, s_{6}\right],\left[s_{6}, s_{6}\right]\right)$ & $\left(\left[s_{4}, s_{6}\right],\left[s_{6}, s_{6}\right],\left[s_{1}, s_{3}\right]\right)$ & - \\
The proposed method & $\left(\left[s_{5}, s_{6}\right],\left[s_{5}, s_{6}\right],\left[s_{6}, s_{6}\right]\right)$ & $\left(\left[s_{4}, s_{6}\right],\left[s_{4}, s_{6}\right],\left[s_{1}, s_{3}\right]\right)$ & - \\
\hline
\end{tabular}

(2) The ranking of alternatives: In the symbolic aggregation-based method, on the basis of the core information of each alternative, a binary preference relation $p\left(a_{j}>a_{j^{\prime}}\right)$ between two alternatives is calculated on the basis of Equation (7); then the nondominance degree $\left(\mathrm{NDD}_{j}\right)$ of each alternative is used to obtain the set of nondominated alternatives, which indicates the degree to which alternative $a_{j}$ is not dominated by the remaining alternatives.

In the HFL-VIKOR method, the hesitant fuzzy linguistic group utility measure $\mathrm{HFLGU}_{j}$ and the hesitant fuzzy individual regret measure HFLIR for the alternative $a_{j}$ are defined by the hesitant fuzzy linguistic Euclidean $L_{p}$-metric; then the hesitant fuzzy linguistic compromise measure HFLC $_{j}$ is established, that is,

$$
\mathrm{HFLC}_{j}=\theta \frac{\mathrm{HFLGU}_{j}-\mathrm{HFLGU}^{+}}{\mathrm{HFLGU}^{-}-\mathrm{HFLGU}^{+}}+(1-\theta) \frac{\mathrm{HFLIR}_{j}-\mathrm{HFLIR}^{+}}{\mathrm{HFLIR}^{-}-\mathrm{HFLIR}^{+}}
$$

in which, $\mathrm{HFLGU}^{+}=\min \left\{\mathrm{HFLGU}_{1}, \mathrm{HFLGU}_{2}, \mathrm{HFLGU}_{3}\right\}, \mathrm{HFLGU}^{-}=\max \left\{\mathrm{HFLGU}_{1}, \mathrm{HFLGU}_{2}\right.$, $\left.\mathrm{HFLGU}_{3}\right\}, \mathrm{HFLIR}^{+}=\min \left\{\mathrm{HFLIR}_{1}, \mathrm{HFLIR}_{2}, \mathrm{HFLIR}_{3}\right\}$ and HFLIR ${ }^{-}=\max \left\{\mathrm{HFLIR}_{1}, \mathrm{HFLIR}_{2}\right.$, $\left.\operatorname{HFLIR}_{3}\right\} ; \theta \in[0,1]$ is the weight of the strategy of the majority of the criteria or the maximum overall utility. By ranking HFLGU ${ }_{j}, \mathrm{HFLIR}_{j}$ and $\mathrm{HFLC}_{j}$ in descending order, the final optimal solution should be that which makes these measures attain the minimum values.

In the proposed method, positive- and negative-ideal separation matrices $D^{+}$and $D^{-}$are used to obtain the relative closeness degree $R C\left(a_{j}\right)$ of each alternative, that is,

$$
\begin{aligned}
D^{+}= & \left(\begin{array}{l}
d\left(\left[s_{4}, s_{6}\right],\left[s_{5}, s_{6}\right]\right)+d\left(\left[s_{5}, s_{6}\right],\left[s_{5}, s_{6}\right]\right)+d\left(\left[s_{4}, s_{6}\right],\left[s_{6}, s_{6}\right]\right) \\
d\left(\left[s_{4}, s_{6}\right],\left[s_{5}, s_{6}\right]\right)+d\left(\left[s_{4}, s_{6}\right],\left[s_{5}, s_{6}\right]\right)+d\left(\left[s_{1}, s_{3}\right],\left[s_{6}, s_{6}\right]\right) \\
d\left(\left[s_{5}, s_{6}\right],\left[s_{5}, s_{6}\right]\right)+d\left(\left[s_{4}, s_{6}\right],\left[s_{5}, s_{6}\right]\right)+d\left(\left[s_{6}, s_{6}\right],\left[s_{6}, s_{6}\right]\right)
\end{array}\right) \doteq\left(\begin{array}{c}
0.67 \\
0.84 \\
0.17
\end{array}\right) \\
D^{-}= & \left(\begin{array}{l}
d\left(\left[s_{4}, s_{6}\right],\left[s_{4}, s_{6}\right]\right)+d\left(\left[s_{5}, s_{6}\right],\left[s_{4}, s_{6}\right]\right)+d\left(\left[s_{4}, s_{6}\right],\left[s_{1}, s_{3}\right]\right) \\
d\left(\left[s_{4}, s_{6}\right],\left[s_{4}, s_{6}\right]\right)+d\left(\left[s_{4}, s_{6}\right],\left[s_{4}, s_{6}\right]\right)+d\left(\left[s_{1}, s_{3}\right],\left[s_{1}, s_{3}\right]\right) \\
d\left(\left[s_{5}, s_{6}\right],\left[s_{4}, s_{6}\right]\right)+d\left(\left[s_{4}, s_{6}\right],\left[s_{4}, s_{6}\right]\right)+d\left(\left[s_{6}, s_{6}\right],\left[s_{1}, s_{3}\right]\right)
\end{array}\right) \doteq\left(\begin{array}{c}
0.67 \\
0 \\
0.67
\end{array}\right) \\
R C\left(a_{1}\right)= & \frac{0.17}{0.67}+\frac{0.67}{0.67} \doteq 1.25, R C\left(a_{2}\right)=\frac{0.17}{0.84}+0 \doteq 0.20, R C\left(a_{3}\right)=2
\end{aligned}
$$

Table 7 shows the ranking comparison of the three methods.

Table 7. The ranking comparison of the three methods.

\begin{tabular}{cccc}
\hline & NDD $_{\boldsymbol{j}}$, HFLC $_{\boldsymbol{j}}$ or $\boldsymbol{R C}\left(\boldsymbol{a}_{\boldsymbol{j}}\right)$ & The Ranking & The Best \\
\hline The method [24] & $(0,0.5,1)$ & $a_{1} \prec a_{2} \prec a_{3}$ & $a_{3}$ \\
The method [45] & $\left(0^{*}, 1^{-}, 0.6074\right)$ & $a_{2} \prec a_{3} \prec a_{1}$ & $a_{1}$ \\
The proposed method & $(1.25,0.20,2)$ & $a_{2} \prec a_{1} \prec a_{3}$ & $a_{3}$ \\
\hline
\end{tabular}

\subsection{Comparison with Beg and Rashid's Method}

Beg and Rashid's method is also called the hesitant fuzzy linguistic TOPSIS (HFL-TOPSIS) method [63] and was used to carry out Example 4, as follows: 
(1) On the basis of Equations (1) and (2), we aggregate $D_{1}, D_{2}$ and $D_{3}$ to obtain the one decision matrix $D$ :

$$
\begin{aligned}
D & \left.=\left(\left[\min _{\max }^{3}\left(\operatorname{mine}_{j k}^{i}\right), \min _{i=1}^{3}\left(\max _{j k}^{i}\right)\right\}, \max \left\{\max _{i=1}^{3}\left(\operatorname{mine}_{j k}^{i}\right), \min _{i=1}^{3}\left(\operatorname{maxe}_{j k}^{i}\right)\right\}\right]\right)_{3 \times 3} \\
& =\left(\begin{array}{lll}
{\left[s_{4}, s_{4}\right]} & {\left[s_{5}, s_{5}\right]} & {\left[s_{5}, s_{5}\right]} \\
{\left[s_{5}, s_{5}\right]} & {\left[s_{4}, s_{4}\right]} & {\left[s_{3}, s_{3}\right]} \\
{\left[s_{4}, s_{5}\right]} & {\left[s_{4}, s_{4}\right]} & {\left[s_{5}, s_{6}\right]}
\end{array}\right)
\end{aligned}
$$

(2) On the basis of Equations (3) and (4), we calculate the HFLTS positive- and negative-ideal solutions $A^{+}$and $A^{-}$; here, we suppose that the criteria are beneficial, that is,

$$
A^{+}=\left(\left[s_{5}, s_{6}\right],\left[s_{5}, s_{6}\right],\left[s_{6}, s_{6}\right]\right), A^{-}=\left(\left[s_{2}, s_{4}\right],\left[s_{3}, s_{4}\right],\left[s_{1}, s_{3}\right]\right)
$$

(3) On the basis of the distance $d\left(H_{S}^{1}, H_{S}^{2}\right)=\left|q^{\prime}-q\right|+\left|p^{\prime}-p\right|$ between $H_{S}^{1}$ and $H_{S^{2}}^{2}$, we obtain the positive (negative)-ideal matrices $D^{+}\left(D^{-}\right)$between $D$ and $A^{+}\left(A^{-}\right)$, that is,

$$
\begin{aligned}
D^{+}= & \left(\begin{array}{l}
d\left(\left[s_{4}, s_{4}\right],\left[s_{5}, s_{6}\right]\right)+d\left(\left[s_{5}, s_{5}\right],\left[s_{5}, s_{6}\right]\right)+d\left(\left[s_{5}, s_{5}\right],\left[s_{6}, s_{6}\right]\right) \\
d\left(\left[s_{5}, s_{5}\right],\left[s_{5}, s_{6}\right]\right)+d\left(\left[s_{4}, s_{4}\right],\left[s_{5}, s_{6}\right]\right)+d\left(\left[s_{3}, s_{3}\right],\left[s_{6}, s_{6}\right]\right) \\
d\left(\left[s_{4}, s_{5}\right],\left[s_{5}, s_{6}\right]\right)+d\left(\left[s_{4}, s_{4}\right],\left[s_{5}, s_{6}\right]\right)+d\left(\left[s_{5}, s_{6}\right],\left[s_{6}, s_{6}\right]\right)
\end{array}\right)=\left(\begin{array}{c}
6 \\
10 \\
6
\end{array}\right) \\
D^{-}= & \left(\begin{array}{l}
d\left(\left[s_{4}, s_{4}\right],\left[s_{2}, s_{4}\right]\right)+d\left(\left[s_{5}, s_{5}\right],\left[s_{3}, s_{4}\right]\right)+d\left(\left[s_{5}, s_{5}\right],\left[s_{1}, s_{3}\right]\right) \\
d\left(\left[s_{5}, s_{5}\right],\left[s_{2}, s_{4}\right]\right)+d\left(\left[s_{4}, s_{4}\right],\left[s_{3}, s_{4}\right]\right)+d\left(\left[s_{3}, s_{3}\right],\left[s_{1}, s_{3}\right]\right) \\
d\left(\left[s_{4}, s_{5}\right],\left[s_{2}, s_{4}\right]\right)+d\left(\left[s_{4}, s_{4}\right],\left[s_{3}, s_{4}\right]\right)+d\left(\left[s_{5}, s_{6}\right],\left[s_{1}, s_{3}\right]\right)
\end{array}\right)=\left(\begin{array}{c}
11 \\
7 \\
9
\end{array}\right)
\end{aligned}
$$

According to $D^{+}$and $D^{-}$, we can obtain the relative closeness (Equation (6)) of each alternative to the ideal solution; Table 8 shows the comparison of the HFL-TOPSIS method and the proposed method.

Table 8. The comparison of the HFL-TOPSIS method and the proposed method.

\begin{tabular}{cccccc}
\hline & Weights & HPIS and HNIS & $\boldsymbol{R C}\left(\boldsymbol{a}_{j}\right)$ & The Ranking & The Best \\
\hline The method [63] & - & $\begin{array}{l}\left(\left[s_{5}, s_{6}\right],\left[s_{5}, s_{6}\right],\left[s_{6}, s_{6}\right]\right) \\
\left(\left[s_{2}, s_{4}\right],\left[s_{3}, s_{4}\right],\left[s_{1}, s_{3}\right]\right)\end{array}$ & $(0.65,0.41,0.6)$ & $a_{2} \prec a_{3} \prec a_{1}$ & $a_{1}$ \\
\hline The proposed method & $\sqrt{ }$ & $\begin{array}{l}\left(\left[s_{5}, s_{6}\right],\left[s_{5}, s_{6}\right],\left[s_{5}, s_{6}\right]\right) \\
\left(\left[s_{3}, s_{5}\right],\left[s_{3}, s_{5}\right],\left[s_{2}, s_{3}\right]\right)\end{array}$ & $(2,0.92,1.1)$ & $a_{2} \prec a_{3} \prec a_{1}$ & $a_{1}$ \\
\hline
\end{tabular}

Comparing the above-mentioned steps (1)-(3) with steps (1)-(6) of Example 4, we can notice the following differences between the HFL-TOPSIS method and the proposed method: (a) The HFLTS positive- and negative-ideal solutions are different; in the HFL-TOPSIS method, the decision matrices of decision making are first aggregated by using operations min and $\max$ (Equations (1) and (2)); then the HFLTS positive- and negative-ideal solutions $A^{+}$and $A^{-}$are obtained by using operations min and max (Equations (3) and (4)), for which, the weights of decision makers or criteria are not considered. In the proposed method, the weights of decision makers are used to aggregate the positive and negative information of decision makers and obtain the HFLTS positive- and negative-ideal solutions (Equations (11)-(14)). (b) The positive- and negative-ideal separation matrices are different; in the HFL-TOPSIS method, $d\left(H_{S}^{1}, H_{S}^{2}\right)=\left|q^{\prime}-q\right|+\left|p^{\prime}-p\right|$ between $H_{S}^{1}$ and $H_{S}^{2}$ is used to obtain the positive- and negative-ideal separation matrices, which satisfy three properties of the distance. In the proposed method, the pseudo-distance between HFLTSs (Equation (8)) is used to obtain the positiveand negative-ideal separation matrices, which are based on preference degrees between two HFLTSs. (c) The relative closeness degrees of the HFL-TOPSIS method and the proposed method are different. 


\section{Conclusions}

Motivated by the TOPSIS method in decision making, in this paper, we have developed a new hesitant fuzzy linguistic TOPSIS method for group multi-criteria hesitant fuzzy linguistic decision making. In the proposed method, we presented the positive and negative information of $c_{k}$ provided by decision maker $d_{i}$ to express the optimistic and pessimistic information of all alternatives provided by each decision maker. Making use of the weighted 2-tuple linguistic aggregation operator, we aggregated the positive and negative information of $c_{k}$ provided by $m$ decision makers to obtain the HFLTS positive- and negative-ideal solutions. We defined the pseudo-distance between two HFLTSs and used this to measure the distance between assessments of the decision maker and the HFLTS positive- and negative-ideal solutions. On the basis of the obtained positive- and negative-ideal separation matrices, we proposed a new relative closeness degree of each alternative, which could be used to rank all the alternatives; intuitively, the greater the value of the relative closeness degree, the better the alternative. We utilized an example to illustrate the performance, usefulness and effectiveness of the new hesitant fuzzy linguistic TOPSIS method, and compared it with the symbolic aggregation-based method, the HFL-TOPSIS method and the HFL-VIKOR method.

It seems that the pseudo-distance between two HFLTSs and the relative closeness degree of the alternative are useful and alternative tools in hesitant fuzzy linguistic decision making. We will use the two concepts in the other decision making method and consider the proposed hesitant fuzzy linguistic TOPSIS to carry out hesitant fuzzy linguistic decision making with huge amounts of decision information and alternatives in the future works.

Acknowledgments: This work has been partially supported by the Research and Development of Petroleum Equipment and Manufacturing Technology Science Foundation of Yan'an (Grant No. 2017WZZ-03-02) and the National Natural Science Foundation of China (Grant No.61372187).

Author Contributions: Fangling Ren wrote the paper; Mingming Kong provided Algorithm 1 and Example 4; Zheng Pei proposed the topic and improved the idea and presentation of the paper.

Conflicts of Interest: The authors declare no conflict of interest.

\section{References}

1. Pedrycz, W.; Chen, S.M. Granular Computing and Decision-Making: Interactive and Iterative Approaches; Springer: Berlin/Heidelberg, Germany, 2015.

2. Watróbski, J.; Sałabun, W. The characteristic objects method: A new intelligent decision support tool for sustainable manufacturing. In Sustainable Design and Manufacturing; Springer: Berlin/Heidelberg, Germany, 2016; pp. 349-359.

3. Watróbski, J.; Sałabun, W.; Ladorucki, G. The temporal supplier evaluation model based on multicriteria decision analysis methods. In Asian Conference on Intelligent Information and Database Systems; Springer: Cham, Switzerland, 2017; pp. 432-442.

4. Faizi, S.; Rashid, T.; Sałabun, W.; Zafar, S.; Watróbski, J. Decision making with uncertainty using hesitant fuzzy sets. Int. J. Fuzzy Syst. 2017, 9, 1-11.

5. Hwang, C.L.; Yoon, K. Multiple Attribute Decision Making: Methods and Applications; Springer: New York, NY, USA, 1981.

6. $\mathrm{Xu}, \mathrm{Z}$.; Wang, H. Managing multi-granularity linguistic information in qualitative group decision making: An overview. Granul. Comput. 2016, 1, 21-35.

7. Chatterjee, K.; Kar, S. Unified Granular-number based AHP-VIKOR multi-criteria decision framework. Granul. Comput. 2017, 2, 199-221.

8. Mendel, J.M. A comparison of three approaches for estimating (synthesizing) an interval type-2 fuzzy set model of a linguistic term for computing with words. Granul. Comput. 2016, 1, 59-69.

9. $\mathrm{Xu}, \mathrm{Z}$; Gou, X. An overview of interval-valued intuitionistic fuzzy information aggregations and applications. Granul. Comput. 2017, 2, 13-39. 
10. Piegat, A.; Sałabun, W. Comparative analysis of MCDM methods for assessing the severity of chronic liver disease. In International Conference on Artificial Intelligence and Soft Computing; Springer: Cham, Switzerland, 2015; pp. 228-238.

11. Liu, P. Multiple attribute decision-making methods based on normal intuitionistic fuzzy interaction aggregation operators. Symmetry 2017, 9, 261.

12. Das, S.; Kar, S.; Pal, T. Robust decision making using intuitionistic fuzzy numbers. Granul. Comput. 2017, 2, 41-54.

13. Najariyan, M.; Mazandarani, M.; John, R. Type-2 fuzzy linear systems. Granul. Comput. 2017, 2, 175-186.

14. Meng, S.; Liu, N.; He, Y. GIFIHIA operator and its application to the selection of cold chain logistics enterprises. Granul. Comput. 2017, 2, 187-197.

15. Qin, J. Interval type-2 fuzzy Hamy mean operators and their application in multiple criteria decision making. Granul. Comput. 2017, 2, 249-269.

16. Pinar, A.J.; Anderson, D.T.; Havens, T.C.; Zare, A.; Adeyeba, T. Measures of the Shapley index for learning lower complexity fuzzy integrals. Granul. Comput. 2017, 2, 303-319.

17. Wang, C.; Fu, X.; Meng, S.; He, Y. Multi-attribute decision making based on the SPIFGIA operators. Granul. Comput. 2017, 2, 321-331.

18. Liu, P.; You, X. Probabilistic linguistic TODIM approach for multiple attribute decision making. Granul. Comput. 2017, 2, 333-342.

19. Jiang, Y.; Xu, Z.; Shu, Y. Interval-valued intuitionistic multiplicative aggregation in group decision making. Granul. Comput. 2017, 2, 387-407.

20. Gligorić, M.; Gligorić, Z.; Beljić, Č.; Torbica, S.; Štrbac Savić, S.; Nedeljković Ostojić, J. Multi-attribute technological modeling of coal deposits based on the fuzzy TOPSIS and C-Mean Clustering Algorithms. Energies 2016, 9, 1059.

21. Bashir, Z.; Wątróbski, J.; Rashid, T.; Sałabun, W.; Ali, J. Intuitionistic-fuzzy goals in zero-sum multi criteria matrix games. Symmetry 2017, 9, 158.

22. Becker, J.; Becker, A.; Saabun, W. Construction and use of the ANP decision model taking into account the experts'competence. Procedia Comput. Sci. 2017, 112, 2269-2279.

23. Liu, Z.; Qin, K.; Pei, Z. A method for fuzzy soft sets in decision-making based on an ideal solution. Symmetry 2017, 9, 246.

24. Rodríguez, R.M.; Martínez, L.; Herrera, F. Hesitant fuzzy linguistic term sets for decision making. IEEE Trans. Fuzzy Syst. 2012, 20, 109-119.

25. Torra, V. Hesitant fuzzy sets. Int. J. Intell. Syst. 2010, 25, 529-539.

26. Zadeh, L.A. The concept of a linguistic variable and its applications to approximate reasoning-Part I. Inf. Sci. 1975, 8, 199-249.

27. Lee, L.-W.; Chen, S.-M. Fuzzy decision making based on likelihood-based comparison relations of hesitant fuzzy linguistic term sets and hesitant fuzzy linguistic operators. Inf. Sci. 2015, 294, 513-529.

28. Wei, C.P.; Zhao, N.; Tang, X.J. Operators and comparisons of hesitant fuzzy linguistic term sets. IEEE Trans. Fuzzy Syst. 2014, 22, 575-584.

29. Liu, H.B.; Rodríguez, R.M. A fuzzy envelope of hesitant fuzzy linguistic term set and its application to multicriteria decision making. Inf. Sci. 2014, 258, 220-238.

30. Montserrat-Adell, J.; Agell, N.; Sánchez, M.; Prats, F.; Ruiz, F.J. Modeling group assessments by means of hesitant fuzzy linguistic term sets. J. Appl. Log. 2016, doi:10.1016/j.jal.2016.11.005.

31. Rodríguez, R.M.; Martínez, L.; Herrera, F. A group decision making model dealing with comparative linguistic expressions based on hesitant fuzzy linguistic term sets. Inf. Sci. 2013, 241, $28-42$.

32. Chen, Z.S.; Chin, K.S.; Li, Y.L.; Yang, Y. Proportional hesitant fuzzy linguistic term set for multiple criteria group decision making. Inf. Sci. 2016, 357, 61-87.

33. Dong, Y.C.; Li, C.C.; Herrera, F. Connecting the linguistic hierarchy and the numerical scale for the 2-tuple linguistic model and its use to deal with hesitant unbalanced linguistic information. Inf. Sci. 2016, 367-368, 259-278.

34. Meng, F.; Chen, X.; Zhang, Q. Multi-attribute decision analysis under a linguistic hesitant fuzzy environment. Inf. Sci. 2014, 267, 287-305. 
35. Riera, J.V.; Massanet, S.; Herrera-Viedma, E.; Torrens, J. Some interesting properties of the fuzzy linguistic model based on discrete fuzzy numbers to manage hesitant fuzzy linguistic information. Appl. Soft Comput. 2015, 36, 383-391.

36. Wang, H. Extended hesitant fuzzy linguistic term sets and their aggregation in group decision making. Int. J. Comput. Intell. Syst. 2015, 8, 14-33.

37. Wang, H.; Xu, Z.S. Total orders of extended hesitant fuzzy linguistic term sets: Definitions, generations and applications. Knowl. Based Syst. 2016, 107, 142-154.

38. Wu, Z.B.; Xu, J.P. Possibility distribution-based approach for MAGDM with hesitant fuzzy linguistic information. IEEE Trans. Cybern. 2016, 46, 694-705.

39. Gou, X.J.; Xu, Z.S.; Liao, H.C. Hesitant fuzzy linguistic entropy and cross-entropy measures and alternative queuing method for multiple criteria decision making. Inf. Sci. 2017, 388-389, 225-246.

40. Liao, H.C.; Xu, Z.S. Approaches to manage hesitant fuzzy linguistic information based on the cosine distance and similarity measures for HFLTSs and their application in qualitative decision making. Expert Syst. Appl. 2015, 42, 5328-5336.

41. Liao, H.C.; Xu, Z.S.; Zeng, X.J. Distance and similarity measures for hesitant fuzzy linguistic term sets and their application in multi-criteria decision making. Inf. Sci. 2014, 271, 125-142.

42. Zhu, B.; Xu, Z.S. Consistency measures for hesitant fuzzy linguistic preference relations. IEEE Trans. Fuzzy Syst. 2014, 22, 35-45.

43. Gao, J.W.; Yi, R. Cloud generalized power ordered weighted average operator and its application to linguistic group decision-making. Symmetry 2017, 9, 156.

44. Chang, K.-H. A more general reliability allocation method using the hesitant fuzzy linguistic term set and minimal variance OWGA weights. Appl. Soft Comput. 2017, 56, 589-596.

45. Liao, H.C.; Xu, Z.S.; Zeng, X.J. Hesitant fuzzy linguistic VIKOR method and its application in qualitative multiple crideria decision making. IEEE Trans. Fuzzy Syst. 2015, 23, 1343-1355.

46. Liao, H.C.; Xu, Z.S.; Zeng, X.J.; Merigó, J.M. Qualitative decision making with correlation coefficients of hesitant fuzzy linguistic term sets. Knowl. Based Syst. 2015, 76, 127-138.

47. Faizi, S.; Sałabun, W.; Rashid, T.; Wątróbski, J.; Zafar, S. Group decision-making for hesitant fuzzy sets based on characteristic objects method. Symmetry 2017, 9, 136.

48. Yue, Z. TOPSIS-based group decision-making methodology in intuitionistic fuzzy setting. Inf. Sci. 2014, 277, 141-153.

49. Boran, F.; Gene, S.; Kurt, M.; Akay, D. A multi-criteria intuitionistic fuzzy group decision making for supplier selection with TOPSIS method. Expert Syst. Appl. 2009, 36, 11363-11368.

50. Chen, T.Y. Interval-valued fuzzy TOPSIS method with leniency reduction and an experimental analysis. Appl. Soft Comput. 2011, 11, 4591-4606.

51. Park, J.H.; Park, I.Y.; Kwun, Y.C.; Tan, X.G. Extension of the TOPSIS method for decision making problems under interval-valued intuitionistic fuzzy environment. Appl. Math. Model. 2011, 35, 2544-2556.

52. Roszkowska, E.; Wachowicz, T. Application of fuzzy TOPSIS to scoring the negotiation offers in ill-structured negotiation problems. Eur. J. Oper. Res. 2015, 242, 920-932.

53. Shih, H.; Shyur, H.; Lee, E. An extension of TOPSIS for group decision making. Math. Comput. Model. 2007, 45, 801-813.

54. Yue, Z. A method for group decision-making based on determining weights of decision makers using TOPSIS. Appl. Math. Model. 2001, 35, 1926-1936.

55. Yue, Z. An extended TOPSIS for determining weights of decision makers with interval numbers. Knowl. Based Syst. 2011, 24, 146-153.

56. Chen, C.T. Extensions of the TOPSIS for group decision-making under fuzzy environment. Fuzzy Sets Syst. 2000, 114, 1-9.

57. Ashtiani, B.; Haghighirad, F.; Makui, A.; Montazer, G. Extension of fuzzy TOPSIS method based on interval-valued fuzzy sets. Appl. Soft Comput. 2009, 9, 457-461.

58. He, Y.Y.; Gong, Z.W. Extension of TOPSIS for intuitionistic fuzzy multiple attribute decision making and experimental analysis. Adv. Inf. Sci. Serv. Sci. 2012, 4, 397-405.

59. Liu, S.; Yu, F.; Xu, W.; Zhang, W. New approach to MCDM under interval-valued intuitionistic fuzzy environment. Int. J. Mach. Learn. Cybern. 2013, 4, 671-678.

60. Yue, Z. Group decision making with multi-attribute interval data. Inf. Fusion 2013, 14, 551-561. 
61. Liang, W.Z.; Zhao, G.Y.; Wu, H. Evaluating investment risks of metallic mines using an extended TOPSIS method with linguistic neutrosophic numbers. Symmetry 2017, 9, 1-18.

62. Sałabun, W. The mean error estimation of TOPSIS method using a fuzzy reference models. J. Theor. Appl. Comput. Sci. 2013, 7, 40-50.

63. Beg, I.; Rashid, T. TOPSIS for hesitant fuzzy linguistic term sets. Int. J. Intell. Syst. 2013, 28, 1162-1171.

64. Wang, Y.M.; Yang, J.B.; Xu, D.L. A preference aggregation method through the estimation of utility intervals. Comput. Oper. Res. 2005, 32, 2027-2049.

65. Wang, J.Q.; Wang, J.; Chen, Q.H.; Zhang, H.Y.; Chen, X.H. An outranking approach for multi-criteria decision-making with hesitant fuzzy linguistic term sets. Inf. Sci. 2014, 280, 338-351.

66. Martínez, L.; Rodriguez, R.M.; Herrera, F. The 2-Tuple Linguistic Model-Computing with Words in Decision Making; Springer: Cham, Switzerland, 2015.

67. Herrera, F.; Martinez, L. A 2-tuple fuzzy linguistic representation model for computing with words. IEEE Trans. Fuzzy Syst. 2000, 8, 746-752.

(C) 2017 by the authors. Licensee MDPI, Basel, Switzerland. This article is an open access article distributed under the terms and conditions of the Creative Commons Attribution (CC BY) license (http:// creativecommons.org/licenses/by/4.0/). 